Aus der Abteilung Urologie

(Prof. Dr. med. R.-H. Ringert)

im Zentrum Chirurgie

der Medizinischen Fakultät der Universität Göttingen

\title{
Die Wnt-Signalkette in der Pathophysiologie der kongenitalen obstruktiven Uropathie der Ratte
}

\author{
INAUGURAL - DISSERTATION \\ zur Erlangung des Doktorgrades \\ der Medizinischen Fakultät \\ der Georg-August-Universität zu Göttingen \\ vorgelegt von \\ Jan-Simon Nikolas Hermens \\ aus \\ Dinslaken
}

Göttingen 2010 
Dekan: Prof. Dr. med. C. Frömmel

1. Berichterstatter: Prof. Dr. med. Seseke

2. Berichterstatter: Prof. Dr. rer. nat. Wodarz

3. Berichterstatterin: Prof. Dr. med. Hahn

Tag der mündlichen Prüfung: 04.08.2010 


\section{Abkürzungsverzeichnis}

\section{A}

Abb.

as-Primer

bp

bzw.

C

$\mathrm{Ca}$

ca.

cDNA

d.h.

DNA

dNTP

EGF

et al.

evtl.

$\mathrm{Fa}$

friz-1 / -2

g

G

HYN

$\mathrm{H}_{2} \mathrm{O}$

IGF

JNK

$\mathrm{KL}$

$\mathrm{KO}$

LW

$\min$.

$\mathrm{mM}$

o.g.

$\mathrm{p}$

PBGD
Adenin

Abbildung

antisense-Primer

base-pairs = Basenpaare

beziehungsweise

Cytosin

Calcium

circa

complementary deoxyribonucleic acid $=$ komplementäre

Desoxyribonukleinsäure

das heißt

deoxyribonucleic acid = Desoxyribonukleinsäure

Desoxyribonukleosidtriphosphat

epidermal growth-factor $=$ epidermaler Wachstumsfaktor

und andere

eventuell

Firma

Frizzled-1 / -2 (Rezeptoren)

Erdbeschleunigung ; als SI-Einheit: Gramm

Guanin

Hydronephrose

Wasser

insulin-like growth-factor $=$ insulinverwandter Wachstumsfaktor

c-Jun N-terminale Kinase

kontralateral

Kontrolle

Leerwert

Minute(n)

Millimol

oben genannt

Signifikanz

Porphobilinogen-Desaminase 
PCR

PDGF

RNA

- mRNA

- rRNA

- tRNA

- tcRNA

RPE

RT

$\mathrm{S}$

sec.

sFRP-1 / -2

s-Primer

Tab.

Taq (-Polymerase)

TGF

$\mathrm{U} / \mathrm{min}$

WIF

Wnt

z.B. polymerase chain reaction $=$ Polymerase-Kettenreaktion platelet-derived growth-factor $=$ von Blutplättchen freigesetzter Wachstumsfaktor

ribonucleic acid $=$ Ribonukleinsäure

mitochondriale RNA

ribosomale RNA

transfer-RNA

total cellular RNA = zelluläre Gesamt-RNA

Ribulosephosphat-3-Epimerase

Reverse Transkriptase

Svedberg; Einheit für Sedimentationskoeffizient

Sekunde(n)

secreted Frizzled-related protein $=$ sezernierte, den Frizzled -

Rezeptoren ähnliche Proteine Typ 1 / 2

sense-Primer

Tabelle

Thermus aquaticus (-Polymerase)

transforming growth-factor $=$ transformierender Wachstumsfaktor

Umdrehungen pro Minute

Wnt-Inhibitory factor $=$ Wnt-unterdrückender Faktor

Signalprotein (Name zusammengesetzt aus Wg des Wingless-

Gens und Int des Integrations-Gens)

zum Beispiel 


\section{Inhaltsverzeichnis}

1. Einleitung $\quad 7$

1.1 Theorie zur kongenitalen obstruktiven Uropathie $\quad 7$

1.2 Ziel dieser Arbeit 8

$\begin{array}{ll}\text { 2. Material und Methoden } & 10\end{array}$

2.1 Geräte, Materialien, Chemikalien 10

$\begin{array}{ll}2.1 .1 \text { Geräte } & 10\end{array}$

$\begin{array}{ll}2.1 .2 \text { Materialien } & 10\end{array}$

$\begin{array}{ll}\text { 2.1.3 Chemikalien } & 10\end{array}$

$\begin{array}{ll}\text { 2.2 Materialgewinnung } & 11\end{array}$

2.2.1 Aufzucht der Versuchstiere und Entnahme der Nieren 11

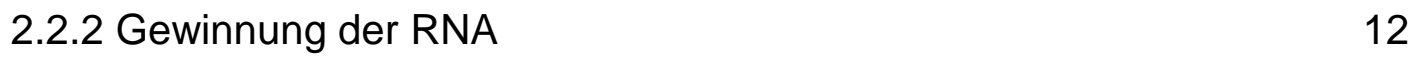

2.3 Quantifizierung der gewonnenen RNA 13

2.3.1 Photometrische Quantifizierung der RNA 13

2.3.2 Quantifizierung und Qualitätsbestimmung der RNA-Proben 14 mittels kapillärer Elektrophorese

2.3.2.1 Prinzip der kapillären Elektrophorese 14

2.3.2.2 Prozedur der RNA-Messung 14

2.4 Bildung von RNA-Pools der einzelnen Versuchsgruppen 15

2.5 cDNA-Synthese 16

2.5.1 Prinzip der reversen Transkription 16

$\begin{array}{ll}2.5 .2 \text { Protokoll } & 16\end{array}$

2.6 Polymerase-Kettenreaktion (PCR) 17

$\begin{array}{ll}\text { 2.6.1 Das Prinzip der PCR } & 17\end{array}$

$\begin{array}{ll}\text { 2.6.2 Die real-time PCR } & 17\end{array}$

2.6.3 Bestimmung der mRNA-Expression mittels real-time PCR 18

2.6.4 Für die PCR verwendete Primer 20

$\begin{array}{ll}\text { 2.6.5 Protokoll der PCR } & 21\end{array}$

2.7 Kontrolle der amplifizierten PCR-Produkte 21

$\begin{array}{ll}\text { 2.7.1 Gel-Elektrophorese } & 21\end{array}$

2.7.2 Schmelzpunktanalyse 22

2.8 Statistische Auswertung der Ergebnisse 23 
3.1 Messverfahren 24

3.2 Housekeeping-Gen 24

3.3 Botenstoffe 25

3.3.1 Wnt 4

3.3.2 Wnt 7b 26

3.4 Rezeptoren 27

3.4.1 Frizzled $1 \quad 27$

3.4.2 Frizzled $2 \quad 28$

3.5 Inhibitoren / Antagonisten 29

3.5.1 SFRP-1 29

3.5.2 SFRP-2 30

3.5.3 WIF-1 31

3.6 Gene der Signalketten 32

3.6.1 JNK 32

3.6.2 Calcineurin 33

3.6.3 B-Catenin 34

3.7 TGF-ß1 35

4. Diskussion $\quad 37$

$\begin{array}{ll}4.1 \text { Wnts } & 37\end{array}$

4.2 Wnt-Rezeptoren 39

4.3 Antagonisten 40

4.4 Die Wnt-Signalketten 42

4.5 Fazit 44

5. Zusammenfassung 46

$\begin{array}{ll}\text { 6. Literaturverzeichnis } & 48\end{array}$ 


\section{Einleitung}

\subsection{Theorie zur kongenitalen obstruktiven Uropathie}

Die Wissenslage über die kongenitale obstruktive Uropathie und einzelne Details ihrer Entwicklung wurde durch verschiedene Tierstudien bereits verbessert. Dennoch ist das Verständnis besonders der frühen Stadien noch unvollständig. In der Therapie der genannten Erkrankung ist die korrekte Differenzierung zwischen einer signifikanten Obstruktion auf der einen sowie einer asymptomatischen Dilatation auf der anderen Seite die größte Schwierigkeit für den behandelnden pädiatrischen Urologen.

Eine Dilatation bedarf außer regelmäßiger Kontrollen keiner weiteren Therapie, wohingegen eine signifikante Obstruktion - sofern sie nicht behandelt wird - zu einem fortschreitenden Verlust der Nierenfunktion führt und damit als eine der Hauptursachen des terminalen Nierenversagens im Kindesalter angesehen werden kann (Najarian et al. 1993).

Konventionelle klinische Methoden wie die Nierenszintigraphie bzw. die Messung der renalen Funktion sind in Bezug auf den Nachweis einer signifikanten Obstruktion relativ ungenau und können so häufig zu falschen Ergebnissen führen. Daher ist die Bestimmung und Etablierung von spezifischen Markern für die renale Obstruktion unabdingbar und würde die Prognose der genannten Erkrankung deutlich verbessern.

Die kongenitale obstruktive Uropathie ist gekennzeichnet durch spezifische molekulare Veränderungen. Das Renin-Angiotensin-System wird aktiviert, was eine Verminderung der renalen Durchblutung und weiterführend eine renale Ischämie zur Folge hat (Chevalier 1999; Klahr 2001; Seseke et al. 2004). Die Aktivität verschiedener Wachstumsfaktoren wie transforming growth-factor B1 (TGF-B1), epidermal growth-factor (EGF), insulin-like growth-factor (IGF) oder platelet-derived growth-factor (PDGF) wird hierdurch maßgeblich beeinflusst (Chevalier 1999; Klahr 2001; Seseke et al. 2004). Zusätzlich wird die Apoptose vorwiegend in Zellen des Tubulussystems gesteigert (Truong et al. 1996; Chevalier 1999; Klahr 2001; Seseke et al. 2004). Zusammengenommen führen diese Änderungen zu für die obstruktive Uropathie spezifischen morphologischen Schäden wie Wachstumsverzögerung, tubuläre Atrophie und interstitielle Fibrose und damit letztendlich zu einem Verlust der renalen Funktion. 
Ein Rückgang der renalen Funktion kann somit bereits Anzeichen irreversibler Veränderungen wie z. B. einer beginnenden interstitiellen Fibrose sein. Die sich klinisch manifestierende Einschränkung der Nierenfunktion zur Beurteilung der therapeutischen Signifikanz der Obstruktion heranzuziehen, birgt also das Problem, dass der optimale Zeitpunkt für eine chirurgische Korrektur der renalen Obstruktion möglicherweise schon überschritten ist.

Das Verständnis der Pathophysiologie insbesondere früher Stadien der kongenitalen obstruktiven Uropathie sowie die Bestimmung eines spezifischen Markers hinsichtlich der verbesserten Differenzierung einer signifikanten kongenitalen Obstruktion ist somit in den Mittelpunkt der Forschungen geraten.

Wnts sind Glykoproteine, die für die interzelluläre Signalübertragung verantwortlich sind. Diese Signalübertragung wird beeinflusst von der Aktivität der Wnts selbst, von inren spezifischen Rezeptoren (Frizzled) und Inhibitoren wie secreted frizzled related proteins (sFRPs), des weiteren beeinflussen der Wnt-Inhibitory factor (WIF-1) sowie Proteine der Dickkopf-Familie die Signalübertragung (Miller 2001; Huelsken und Behrens 2002).

Die angeborene renale Obstruktion hemmt die normale Nephrogenese und die Entwicklung des renalen Wachstums (Chevalier 1995; Seseke et al. 2001). Wnt-4 spielt eine Schlüsselrolle in der normalen Nephrogenese sowie teilweise auch in der Tubulogenese (Vaino 2003). Es ist daher von Interesse, ob Veränderungen in der Wnt-Signalkette in der Pathophysiologie der kongenitalen obstruktiven Uropathie eine Rolle spielen.

\subsection{Ziel dieser Arbeit}

Das Ziel der vorliegenden Arbeit war es, herauszufinden, ob ein Zusammenhang zwischen der Wnt-Signalkette und der Entstehung der kongenitalen obstruktiven Uropathie besteht und weitergehend, welche Schritte der Signalkette von den Änderungen betroffen sind. In einem Tiermodell mit Ratten mit spontaner kongenitaler obstruktiver Uropathie (Tauchi et al. 1980; Seseke et al. 2004) wurden an renaler mRNA die Expressionsmuster verschiedener, an der Wnt-Signalkette beteiligter Gene während der normalen Nephrogenese sowie in späteren Stadien 
der genannten Erkrankung untersucht. Anhand der präsentierten Ergebnisse soll ein experimentelles Modell für die Rolle der Wnt-Signalübertragung in der Pathophysiologie der kongenitalen obstruktiven Uropathie entwickelt werden. 


\section{Material und Methoden}

\subsection{Geräte, Materialien, Chemikalien}

\subsubsection{Geräte}

Folgende Geräte wurden für die experimentelle Arbeit verwendet:

- Pipetten unterschiedlicher Größe: Eppendorf

- Zentrifugen:

Heraeus Labofuge GI, Hanau

Heraeus Labofuge 400R, Hanau

- Photometer: Pharmacia Biotech Gene Quant II

- Nano Chip Priming Station: Agilent Technologies, Waldbronn

- Bioanalyzer: Agilent 2100 Bioanalyzer, Agilent Technologies, Waldbronn

- Homogenisator: IKA ${ }^{\circledR}$ WORKS

- Thermocycler: Techne Genius

- real-time PCR-Cycler: iCycler iQ (BioRAD), München

- Software zur Datenanalyse:

iCycler $\mathrm{iQ}^{\circledR}$ real time detection software

Herolab E.A.S.Y. Win32 zur Auswertung der Gel-Elektrophorese

Microsoft $^{\circledR}$ Excel zur Berechnung der mRNA-Konzentration anhand

Standardkurven

\subsubsection{Materialien}

Nachfolgend aufgelistete Materialien wurden für die Versuche benötigt:

- RNeasy ${ }^{\circledR}$ Mini Kit: QIAGEN, Hilden

- RNA 6000 Nano LabChip ${ }^{\circledR}$ Kit: Agilent Technologies, Waldbronn

\subsubsection{Chemikalien}


Folgende Chemikalien kamen zur Anwendung:

- RNeasy ${ }^{\circledR}$ Mini Kit: QIAGEN, Hilden

- Ethanol p.a. (EtOH): Fluka

- RNA 6000 Nano LabChip ${ }^{\circledR}$ Kit: Agilent Technologies, Waldbronn

- RNA 6000 Leiter: Ambion, Austin, Texas, USA

- RNaseZAP ${ }^{\circledR}$ : Ambion, Austin, Texas, USA

- Omniscript ${ }^{\circledR}$ RT Kit: QIAGEN, Hilden

- RNase Inhibitor: Eppendorf

- Random Primer: QIAGEN

- iQ ${ }^{\top M} S^{\top} Y B R^{\circledR}$ Green Supermix Kit: BioRAD, München

- genspezifische sense- und antisense-Primer sowie Standards: Operon, QIAGEN

\subsection{Materialgewinnung}

\subsubsection{Aufzucht der Versuchstiere und Entnahme der Nieren}

Die untersuchten Nieren wurden aus Ratten einer Kolonie gewonnen, die aus dem von Tauchi et al. 1980 erstmals beschriebenen Inzuchtstamm etabliert wurde (Tauchi et al. 1980). Die Tiere wurden in Kunststoffkäfigen bei einem zwölfstündigen TagNacht-Rhythmus gehalten, Wasser und Nahrung standen ad libitum zur Verfügung. Im Alter von 14 bzw. 32 Tagen wurden die Tiere nach intraperitonealer Injektion von Ketamin mittels Genickbruch getötet. Es wurden innen daraufhin beide Nieren im Ganzen entnommen und für weitere Untersuchungen in flüssigem Stickstoff gefroren. 


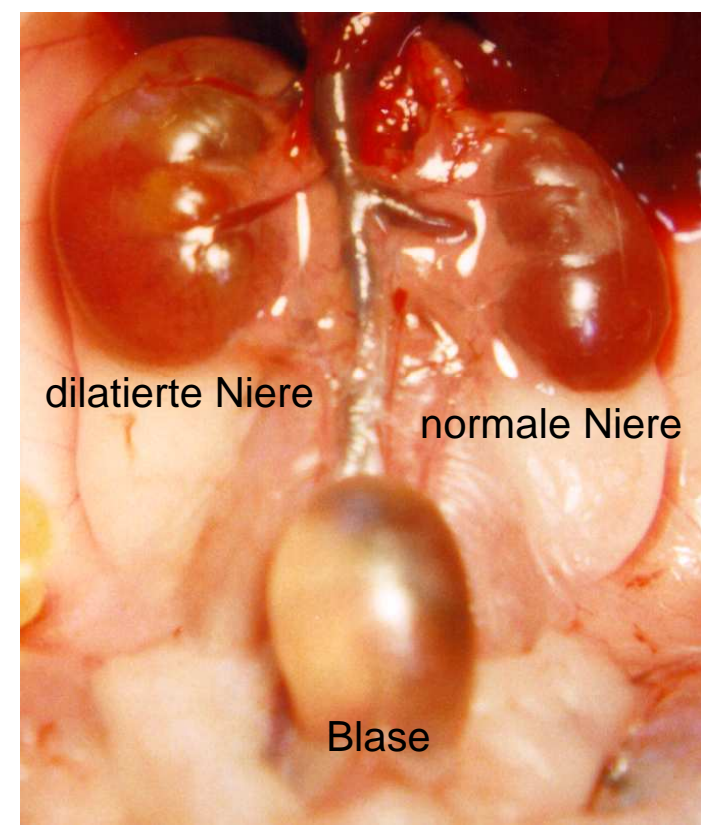

Abb. 2.1: Situs einer 32 Tage alten Ratte mit unilateraler renaler Dilatation (aus Seseke et al. 2004, S. 375)

\subsubsection{Gewinnung der RNA}

Das Prinzip der RNA-Isolation mit dem RNeasy Mini Kit ${ }^{\circledR}$ (Quiagen) macht sich die selektiven Bindungseigenschaften einer auf Silicagel basierenden Membran in Verbindung mit der Technik des Hochgeschwindigkeits-Mikrozentrifugierens zunutze. Ein spezielles Puffersystem mit hohem Salzgehalt bzw. hohem Ethanolgehalt ermöglicht, dass bis zu 100 $\mu \mathrm{g}$ RNA von einer Länge über 200 Basen an der Membran binden. Die zu untersuchenden Proben werden zuerst gelöst und homogenisiert, hierzu ist ein denaturierender Guanidin-Isothiocyanat-haltiger Puffer notwendig, der RNasen inaktiviert und somit die Isolation intakter, kompletter RNA gewährleistet (Chomczynski und Sacchi 1987). Die Zugabe von Ethanol verhindert, dass die gelösten RNA-Stränge untereinander Bindungen eingehen und führt dazu, dass nach Gabe auf die RNeasy Minisäule die komplette RNA an der Silicagelmembran binden kann und Verunreinigungen ausgewaschen werden können. Mit der o.g. Technik werden alle RNA-Moleküle, welche länger als 200 Nukleotide sind, isoliert. 
Der Anteil RNA einer Größe kleiner als 200 Basen setzt sich zusammen aus 5,8S rRNA, $5 S$ rRNA und tRNA und beträgt zwischen 15-20\% der zellulären Gesamt-RNA (tcRNA). Da dieser Anteil im beschriebenen Verfahren selektiert und verworfen wird, wird die mRNA, deren Anteil an der tcRNA ca. 1-5\% beträgt, angereichert und dient für spätere Untersuchungen als Grundlage.

Zu Beginn wurden die in toto entnommenen Nieren in Stücke von 25-30mg zerteilt. Die tiefgefrorenen Gewebestücke wurden in $600 \mu$ l Lysepuffer gelöst, das Gemisch mit einem Shredder homogenisiert. Danach wurde das Gewebelysat 3 Minuten lang zentrifugiert und der Überstand in ein neues Röhrchen pipettiert.

Nach Mischen mit 70\% Ethanol im Verhältnis 1:1 wurde die Probe auf eine RNeasy Minisäule in einem 2-ml-Probengefäß pipettiert und für 15 Sekunden bei $8000 \mathrm{~g}$ zentrifugiert, der Durchfluss wurde verworfen. Nach Zugabe von $700 \mu l$ RW1-Puffer wurde erneut für 15 Sekunden bei $8000 \mathrm{~g}$ zentrifugiert, Durchfluss und Sammelgefäß wurden verworfen und die Säule in ein neues Röhrchen gesetzt. Jetzt wurden $500 \mu \mathrm{l}$ RPE-Puffer auf die Säule pipettiert, zunächst 15 Sekunden bei $8000 \mathrm{~g}$ zentrifugiert

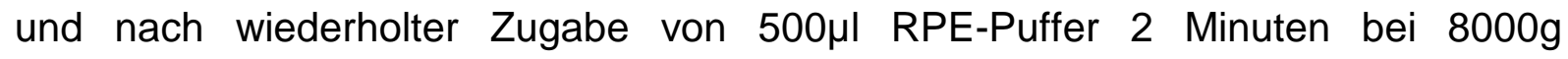
zentrifugiert, um die Silicagelmembran zu trocknen. Nach Wechseln des

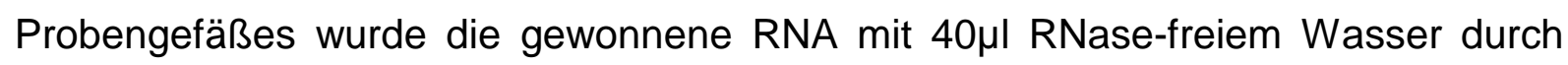
direktes Abspülen von der Membran gelöst. Die Lagerung des RNA-WasserGemisches erfolgte bei $-80^{\circ} \mathrm{C}$.

\subsection{Quantifizierung der gewonnenen RNA}

\subsubsection{Photometrische Quantifizierung der RNA}

Um später sowohl für die 14 Tage alten als auch für die 32 Tage alten Tiere vergleichbare Pools bilden zu können, wurde bei den gewonnenen Proben einzeln die RNA-Konzentration gemessen und anschließend so verdünnt, dass jeweils vergleichbare Konzentrationen vorlagen.

Die Vormessung der RNA erfolgte am Photometer (Gene Quant II, RNA/DNA Calculator, Pharmacia Biotech). Die Ergebnisse dienten als Richtwert für die RNA- 
Quantifizierung mit dem Agilent 2100 Bioanalyzer. Die Konzentration der RNA wurde durch Absorptionsmessung bei $260 \mathrm{~nm}$ bestimmt.

Zur Kalibrierung des Photometers wurde zunächst eine Leerwertbestimmung mit RNase-freiem Wasser durchgeführt. Danach wurden die eigentlichen Messungen vorgenommen. Um Verunreinigungen zu vermeiden, wurde nach jeder Messung die Küvette mit Wasser ausgewaschen.

Die so bestimmten RNA-Konzentrationen lagen zwischen $403 \mathrm{ng} / \mu \mathrm{l}$ und $442 \mathrm{ng} / \mu \mathrm{l}$. Sie dienten als Richtwerte für die daraufhin durchgeführte Quantifizierung mit dem Bioanalyzer 2100.

\subsubsection{Quantifizierung und Qualitätsbestimmung der RNA-Proben mittels kapillärer Elektrophorese}

Die exakte Quantität so wie Integrität der RNA wurde mit dem Agilent Bioanalyzer 2100 mit Hilfe des RNA 6000 Nano LabChip ${ }^{\circledR}$ Kit (Agilent Technologies, Waldbronn, Germany) bestimmt. Die Analysen wurden anhand der Herstellerangaben durchgeführt.

\subsubsection{Prinzip der kapillären Elektrophorese}

Jeder RNA LabChip $^{\circledR}$ enthält ein miteinander verbundenes System von Mikrokanälen, durch welches die Nukleinsäuren größenabhängig gesiebt und im Sinne einer Elektrophorese aufgetrennt werden. Der Bioanalyzer misst die Fluoreszenz der RNA Proben über die Zeit und zeichnet ein Elektropherogramm auf (Abb. 2.2). Zu jeder Messung erstellt die Software außerdem ein Gel-Bild. Weiterhin berechnet das System automatisch das Verhältnis der ribosomalen Banden der RNA und zeigt Verunreinigungen an.

\subsubsection{Prozedur der RNA-Messung}

Die RNA-Messung erfolgte mittels RNA 6000 Nano Assay (Reagant Kit Guide, Fa. Agilent Technologies). Der Chip wurde nach einer festgelegten Prozedur wie folgt 
vorbereitet: mit $9 \mu$ l Gel-Farbstoff-Mix wurde der Chip per Luftdruck 30 Sekunden

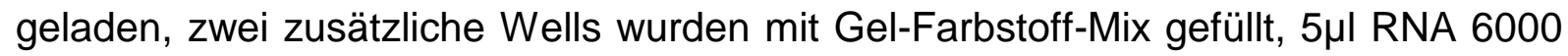
Nano Marker wurden in die übrigen Wells pipettiert, $1 \mu$ leiner RNA-Leiter wurde nach zweiminütigem Erhitzen auf $70^{\circ} \mathrm{C}$ in das Leiter-Well gefüllt und jedes der 12 ProbenWells wurde mit je $1 \mu \mathrm{l}$ der zu messenden RNA-Lösung versehen, nachdem diese zwecks Denaturierung ebenfalls für 2 Minuten auf $70^{\circ} \mathrm{C}$ erhitzt wurden. Dann wurde die Messung mit dem RNA 6000 Nano-Protokoll durchgeführt.

Die Ergebnisse der Agilent ${ }^{\circledR}$-Messung gaben nicht nur Aufschluss über die Quantität, sondern auch über die Qualität der in den Proben enthaltenen RNA, es wurden insbesondere die 18S- und die 28S-Untereinheiten sowie deren Verhältnis zueinander bestimmt.

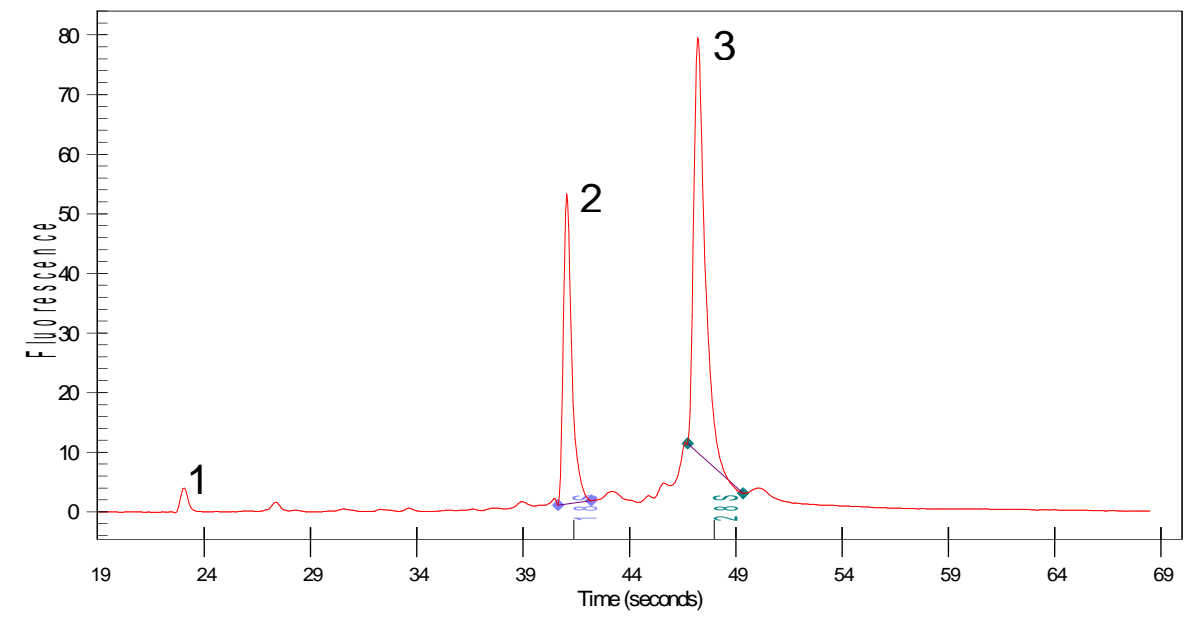

Abb. 2.2: Elektropherogramm des Pools Hydronephrose, 14 Tage alte Tiere 1: Kontroll-Peak, 2: 18S-RNA Peak, 3: 28S-RNA Peak

\subsection{Bildung von RNA-Pools der einzelnen Versuchsgruppen}

Um die Auswertung einer nur individuell unterschiedlichen Genregulation der einzelnen Tiere zu vermeiden, wurden die Proben so gepoolt, dass pro Altersklasse Pools mit jeweils gleichen RNA-Konzentrationen der einzelnen Nieren entstanden. So wurden für die 14tägigen Tiere ein Pool Hydronephrose $(n=5)$, ein Pool Kontralateral $(n=3)$ und ein Pool Kontrolle $(n=6)$ gebildet. Auch bei den 32 Tage alten 
Tieren wurde ein Pool Hydronephrose $(n=16)$, ein Pool Kontralateral $(n=10)$ und ein Pool Kontrolle $(n=4)$ gebildet.

\section{5 cDNA-Synthese}

Zum Umschreiben festgelegter Mengen der isolierten mRNA in cDNA wurde das Omniscript ${ }^{\circledR}$-System der Firma Qiagen ${ }^{\circledR}$ verwendet.

Das Omniscript ${ }^{\circledR}$ RT Kit eignet sich für die Umschreibung von 50 ng bis $2 \mu \mathrm{g}$ GesamtRNA. Da Zufallsprimer (Random Primer) verwendet werden, wird die komplette RNA, einschließlich jeglicher rRNA, mRNA und tRNA, umgeschrieben.

\subsubsection{Prinzip der reversen Transkription}

Die Omniscript Reverse Transkriptase ist ein Enzym mit einer hohen Affinität zur RNA und ermöglicht somit eine effiziente und sensitive Umschreibung von RNA zu einsträngiger cDNA. Die Reverse Transkriptase leitet sich von RNA enthaltenden Retroviren ab. Man versteht hierunter ein multifunktionelles Enzym mit 3 Enzymaktivitäten: eine RNA-abhängige DNA-Polymerase, eine hybridabhängige Exoribonuklease (RNase $\mathrm{H}$ ) und eine DNA-abhängige DNA-Polymerase. Bei retroviralen Infektionen ermöglicht die Kombination dieser 3 Enzymaktivitäten die Umschreibung von einsträngiger RNA in doppelsträngige DNA. Bei der Reversen Transkription in vitro unter Verwendung des QIAGEN Kits werden nur die ersten zwei Enzymaktivitäten ausgenutzt, um einsträngige cDNA herzustellen.

\subsubsection{Protokoll}

Der Grundansatz, bestehend aus $2 \mu \mathrm{l}$ RT-Puffer, $2 \mu \mathrm{l} 5 \mathrm{mM}$ dNTPs, $1 \mu \mathrm{l}$ Reverse

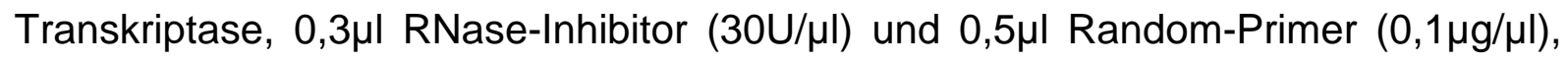
wurde vorbereitet; das später hinzugefügte RNA-Volumen entsprach jeweils 500ng RNA. Die außerdem benötigte Menge an RNase-freiem Wasser wurde so gewählt, dass letztendlich ein Gesamtvolumen von $20 \mu$ l vorlag. 
Im Thermocycler ${ }^{\circledR}$ (Fa. Techne Genius) wurde zunächst nur das RNA-WasserGemisch bei $65^{\circ} \mathrm{C}$ für 5 Minuten inkubiert, anschließ end durchlief das komplette Gemisch die vom Protokoll festgelegten Syntheseschritte, d.h. 60 Minuten bei $37^{\circ} \mathrm{C}$, gefolgt von 5 Minuten bei $93^{\circ} \mathrm{C}$, abschließend Abkühl ung auf $4^{\circ} \mathrm{C}$. Nach Verdünnung der umgeschriebenen cDNA mit jeweils $80 \mu \mathrm{l} \mathrm{H}_{2} \mathrm{O}$ ergaben sich so pro Pool $100 \mu \mathrm{l}$ gebrauchsfertiger cDNA, Konzentration $5 \mathrm{ng} / \mu \mathrm{l}$, für die real-time PCR.

\subsection{Polymerase-Kettenreaktion (PCR)}

\subsubsection{Das Prinzip der PCR}

Das Prinzip der Polymerase-Kettenreaktion (PCR) besteht in einer selektiven Amplifizierung eines definierten DNA-Abschnittes durch Einsatz sequenzspezifischer Primer, welche komplementär zu den $5^{\prime}$-endständigen Basenfolgen beider Stränge der Ursprungs-DNA sein müssen. Für diese Vermehrung eines DNA-Fragmentes werden 3 Schritte benötigt: Zuerst wird der DNA-Doppelstrang bei hoher Temperatur aufgebrochen, danach folgt die Anlagerung des forward-Primers und des reversePrimers an den jeweiligen Einzelstrang (Annealing), im letzten Schritt, der sog. Elongationsphase, werden durch eine zugesetzte Polymerase die komplementären Abschnitte der DNA geschrieben, wofür genügend Nukleotide zur Verfügung stehen müssen.

Nach Abschluss eines solchen Zyklus hat sich die Menge der DNA des gewünschten Bereiches verdoppelt. Durch mehrfache Wiederholung der Schritte wird eine exponentielle Vermehrung der DNA erreicht.

\subsubsection{Die real-time PCR}

Die Methode der Echtzeit-Polymerase-Kettenreaktion (real-time PCR) ist zu einer weit verbreiteten und etablierten Methode der Genquantifizierung geworden, die sich durch hohe Sensibilität und hohe Sequenzspezifität bei weitem Messbereich auszeichnet (Wong und Medrano 2005). 
Bei der real-time PCR werden die Daten bereits während des Prozesses der Amplifizierung gewonnen, was durch den Einsatz verschiedener Fluoreszenzfarbstoffe erreicht wird, deren Intensität mit der Konzentration des PCRProduktes korreliert. Die Fluoreszenz wird direkt ab dem ersten Zyklus der PCR gemessen und mit einer definierten Hintergrundfluoreszenz verglichen. Ein messbarer Konzentrationsanstieg des PCR-Produktes wird verzeichnet, sobald die registrierte Fluoreszenz die Hintergrundfluoreszenz übersteigt. Dieser Zeitpunkt tritt umso eher ein, desto höher die Ausgangskonzentration der Ziel-DNA in der untersuchten Probe ist.

Bei der Polymerase-Kettenreaktion unterscheidet man vier verschiedene Phasen (Wong und Medrano 2005):

1. die lineare Grundphase. Hier übersteigt die gemessene Fluoreszenz die Hintergrundfluoreszenz noch nicht. In dieser Phase, für gewöhnlich mindestens die ersten 15 Zyklen, wird die Grundfluoreszenz registriert.

2. die frühe exponentielle Phase. Hier übersteigt der Fluoreszenzwert erstmals signifikant die zuvor festgelegte Hintergrundfluoreszenz. Der Zyklus, in dem dieser messbare Anstieg erfolgt, wird als sog. Threshold-Zyklus oder auch als crossing point bezeichnet. Er beschreibt den Punkt, an dem erstmals das Zehnfache der nicht signifikanten Fluktuationen der Fluoreszenzsignale gemessen wird. Dieser Wert gibt Aufschluss über die anfängliche Anzahl von Kopien der Ziel-DNA und wird als Grundlage der Ergebnisberechnung verwendet.

3. die logarithmisch-lineare Phase, auch als exponentielle Phase bezeichnet. Hier erreicht die PCR die optimale Amplifizierungsrate der DNA, wobei die Menge des PCR-Produktes in jedem Zyklus verdoppelt wird.

4. die Plateau-Phase. Diese wird erreicht, wenn Reaktionskomponenten aufgebraucht sind.

Ein beispielhafter Kurvenverlauf findet sich in Abbildung 2.3.

\subsubsection{Bestimmung der mRNA-Expression mittels real-time PCR}

Die Expression der in dieser Arbeit untersuchten Gene wurde mit Hilfe des o.g. Verfahrens der real-time PCR bestimmt. Für alle Versuche wurde das SYBR-Green ${ }^{{ }_{-}}$ 
Mastermix-Kit der Firma BioRAD ${ }^{\circledR}$ benutzt. Es wurde nach einem standardisierten Protokoll pipettiert. Zur repräsentativen statistischen Auswertung wurden je Gen und Pool drei Messungen vorgenommen.

Zunächst wurde ein Grundansatz erstellt, bestehend aus einem Vielfachen von je

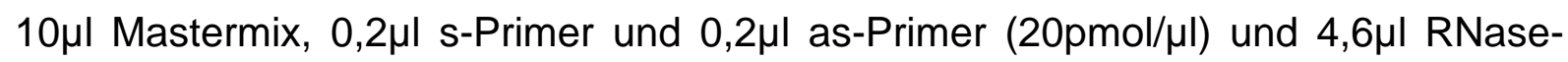
freiem $\mathrm{H}_{2} \mathrm{O}$ pro zu untersuchender Vertiefung auf der Lochplatte (die genaue Beschreibung der im Einzelnen verwendeten Primer erfolgt weiter unten). Nach Zentrifugieren für 2 Minuten bei $10.000 \mathrm{U} / \mathrm{min}$ wurden $15 \mu \mathrm{l}$ dieses Grundansatzes auf die einzelnen PCR-Gefäße verteilt, daraufhin wurden $5 \mu \mathrm{l}$ cDNA $(5 \mathrm{ng} / \mu \mathrm{l})$ der jeweils zu untersuchenden Pools beider Altersklassen hinzugegeben, so dass sich ein gesamtes Probevolumen von $20 \mu$ lergab.

Jetzt wurde die Expressionsquantifizierung mittels real-time PCR im iCycler ${ }^{\circledR}$ der Fa. BioRAD ${ }^{\circledR}$ durchgeführt. Für die einzelnen Gene wurden unterschiedliche Programme verwendet, die sich allerdings nur in der vorgegebenen Annealing-Temperatur für das jeweilige Gen bzw. die jeweiligen Primer unterschieden. Auf der verwendeten 96Lochplatte wurden maximal 2 Gene gleichzeitig in einem Durchlauf untersucht, sofern ihre Annealingtemperaturen übereinstimmten.

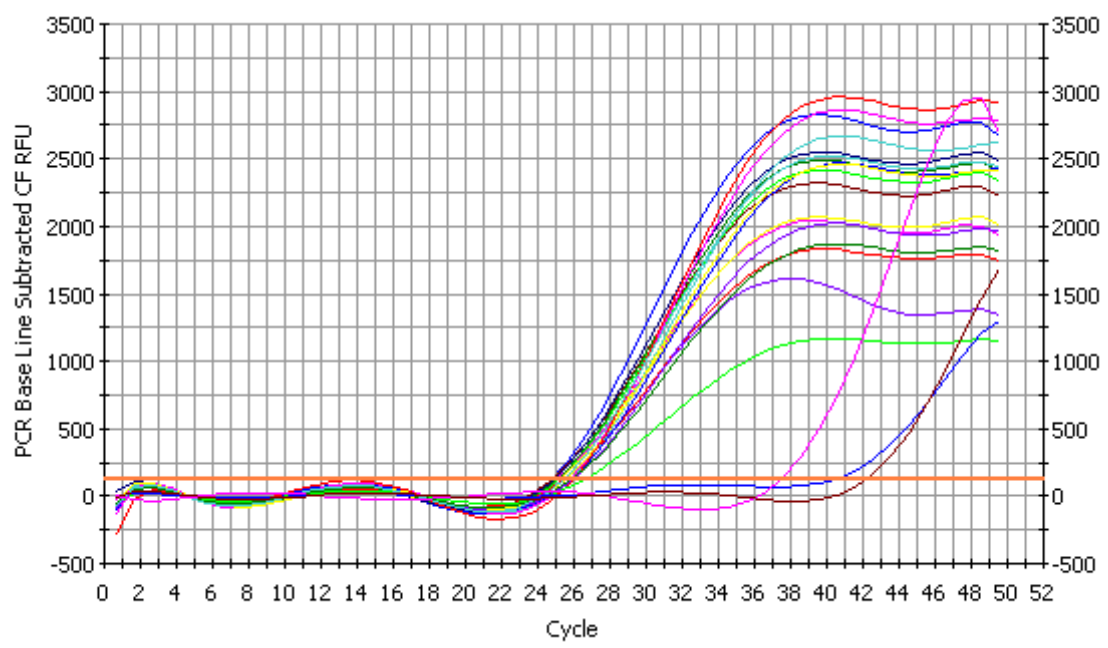

Abb. 2.3: Repräsentative Kurve einer real-time PCR, hier für PBGD. Die orangefarbene Linie markiert den Thresholdwert. Die späten Anstiege jenseits des 35. Zyklus kommen durch amplifizierte unspezifische PCR-Produkte, zumeist Primer-Dimere, in den cDNAfreien Leerproben zustande. 


\subsubsection{Für die PCR verwendete Primer}

Es wurden DNA-Primer einer Länge zwischen 20 und 28 Basen verwendet, je PCR wurde ein sequenzspezifischer forward- und reverse-Primer eingesetzt (Tab. 2.1). Die Primer (Operon, Qiagen) wurden entworfen mit Hilfe des primer3 online primer design program (www-genome.wi.mit.edu/cgi-bin/primer/primer3_www.cgi).

\begin{tabular}{|c|c|c|}
\hline Primer & Basensequenz & $\begin{array}{l}\text { Größe des PCR- } \\
\text { Produktes }\end{array}$ \\
\hline $\begin{array}{l}\text { PBGD forward } \\
\text { PBGD reverse }\end{array}$ & $\begin{array}{l}\text { 5'-TGT CTG GTA ACG GCA ATG CGG CTG CAA C-3' } \\
\text { 5'-TCA ATG TTG CCA CCA CAC TGT CCG TCT-3' }\end{array}$ & $127 \mathrm{bp}$ \\
\hline $\begin{array}{l}\text { Wnt } 4 \text { forward } \\
\text { Wnt } 4 \text { reverse }\end{array}$ & $\begin{array}{l}\text { 5'-AGA TGT GCA AAC GGA ACC TC-3' } \\
\text { 5'-GTC CCT TGT GTC ACC ACC TT-3' }\end{array}$ & $154 \mathrm{bp}$ \\
\hline $\begin{array}{l}\text { Wnt } 7 b \text { forward } \\
\text { Wnt } 7 b \text { reverse }\end{array}$ & $\begin{array}{l}\text { 5'-CCG CTA TGG CAT TGA CTT TT-3' } \\
\text { 5'-TCC AGA ACC AGA CCC TCA TC-3' }\end{array}$ & $153 \mathrm{bp}$ \\
\hline $\begin{array}{l}\text { Friz } 1 \text { forward } \\
\text { Friz } 1 \text { reverse }\end{array}$ & $\begin{array}{l}\text { 5'-GGG CTG TAC CAG CCA TTA AA-3' } \\
\text { 5'-TGC CGA TGA ACA GAT AGA CG-3' }\end{array}$ & $153 \mathrm{bp}$ \\
\hline $\begin{array}{l}\text { Friz } 2 \text { forward } \\
\text { Friz } 2 \text { reverse }\end{array}$ & $\begin{array}{l}\text { 5'-GAA CTC CTG CGC TAC TCA CC-3' } \\
\text { 5'-GAG ATA GGA CGG CAC CTT GA-3' }\end{array}$ & $158 \mathrm{bp}$ \\
\hline $\begin{array}{l}\text { WIF forward } \\
\text { WIF reverse }\end{array}$ & $\begin{array}{l}\text { 5'-TGT GTC ACT CCT GGC TTC TG-3' } \\
\text { 5'-CAC TGC TCT CCC TCA AGT CC-3' }\end{array}$ & $149 \mathrm{bp}$ \\
\hline $\begin{array}{l}\text { sFRP } 1 \text { forward } \\
\text { SFRP } 1 \text { reverse }\end{array}$ & $\begin{array}{l}\text { 5'-CAT GCA GTT CTT CGG CTT CT-3' } \\
\text { 5'-TCG CTT GCA CAG AGA TGT TC-3' }\end{array}$ & $189 \mathrm{bp}$ \\
\hline $\begin{array}{l}\text { SFRP } 2 \text { forward } \\
\text { SFRP } 2 \text { reverse }\end{array}$ & $\begin{array}{l}\text { 5'-ACG GCA TCG AGT ACC AGA AC-3' } \\
\text { 5'-GCT GGA TGG TCT CGT CTA GG-3' }\end{array}$ & $186 \mathrm{bp}$ \\
\hline $\begin{array}{l}\text { JNK forward } \\
\text { JNK reverse }\end{array}$ & $\begin{array}{l}\text { 5'-TGT GGA ATC AAG CAC CTT CAC TCT GCT G-3' } \\
\text { 5'-GCA AAC CAT TTC TCC CAT AAT GCA CCC-3' }\end{array}$ & $252 \mathrm{bp}$ \\
\hline $\begin{array}{l}\text { B-Catenin forward } \\
\text { B-Catenin reverse }\end{array}$ & $\begin{array}{l}\text { 5'-GGT TCA CCA GCT TTC CAA AA-3' } \\
\text { 5'-GAT GCC GCC AGA TTT AAA GA-3' }\end{array}$ & $190 \mathrm{bp}$ \\
\hline
\end{tabular}




\begin{tabular}{|l|l|l|}
\hline Calcineurin forward & 5'-GCA GGC TGG AAG AAA GTG TC-3' & $247 \mathrm{bp}$ \\
Calcineurin reverse & 5'-AAG GCC CAC AAA TAC AGC AC-3' & \\
\hline TGF-1B forward & 5'-CAA GTC AAC TGT GGA GCA AC-3' \\
TGF-1B reverse & 5'-AAC CCA GGT CCT TCC TAA AG-3' & $448 \mathrm{bp}$ \\
\hline
\end{tabular}

Tab. 2.1: Für die PCR verwendete Primer-Sequenzen der einzelnen Gene

\subsubsection{Protokoll der PCR}

Grundlegend galt für alle durchgeführten PCRs die gleiche Abfolge an Arbeitsschritten:

1. Erhitzen der Proben auf $95^{\circ} \mathrm{C}$ für 15 Minuten (Den aturierung der DNA und Aktivierung der Taq-Polymerase)

2. Eigentliche PCR-Zyklen, 50-fache Wiederholung: je $30 \mathrm{sec}$ bei $95^{\circ} \mathrm{C}$ (Aufbrechen der Doppelstrangbindungen), 30sec bei $60^{\circ} \mathrm{C}$ (Anlagerung der Primer an die einzelnen DNA-Stränge) und $30 \mathrm{sec}$ bei $72^{\circ} \mathrm{C}$ (Elongationsphase, Schreiben des komplementären DNA-Stranges).

Die Messung der Fluoreszenz erfolgte jeweils in der Annealing-Phase.

3. Schmelzkurvenbestimmung: Beginnend bei einer Temperatur von $55^{\circ} \mathrm{C}$ Erwärmung der Produkte um je $0,5^{\circ} \mathrm{C}$ alle 10 Sekunden, 80fache Wiederholung bis zum Erreichen der Endtemperatur von $9^{\circ} \mathrm{C}$. Hierbei ständig Bestimmung des Schmelzpunktes des Produktes.

4. Abkühlung und anschließender Hold bei Raumtemperatur (20)

\subsection{Kontrolle der amplifizierten PCR-Produkte}

\subsubsection{Gel-Elektrophorese}

$\mathrm{Da}$ es sich bei dem verwendeten Fluoreszenz-Farbstoff um ein DNA-bindendes Produkt handelt, welches nicht sequenzspezifisch bindet, kann es evtl. zu falschpositiven Werten kommen. Um dieses auszuschließen, wurde mit den PCR- 
Produkten ein Lauf in einem Agarosegel (2\%) durchgeführt, dieses wurde nach Färbung mit Ethidiumbromid zur Erhöhung der Fluoreszenz mittels Densitometrie (Herolab E.A.S.Y Win32) ausgewertet (Abb. 2.4).

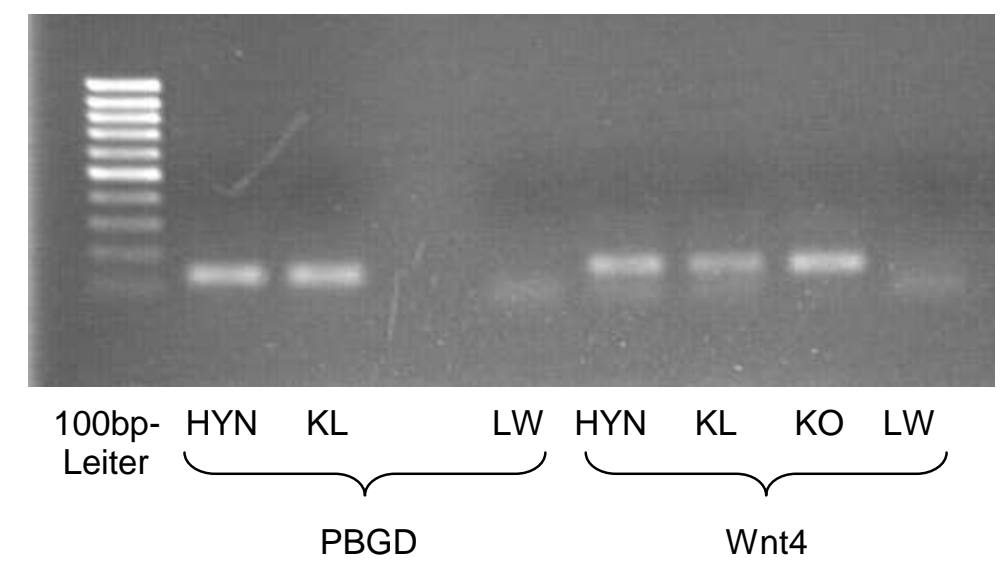

Abb. 2.4: Repräsentative Gel-Elektrophorese der PCR-Produkte für PBGD und Wnt4, 14tägige Tiere $(\mathrm{HYN}=$ Pool hydronephrotische Nieren, $\mathrm{KL}=$ Pool kontralaterale, gesunde Nieren, $\mathrm{KO}=$ Kontrollpool)

\subsubsection{Schmelzpunktanalyse}

Als weiterer Kontrollschritt wurde am Ende jeder PCR eine Schmelzpunktanalyse des amplifizierten Produktes durchgeführt (Abb.2.5), um dessen Richtigkeit zu überprüfen. Die Schmelzpunktanalyse gibt sowohl über die PCR-Produktgröße als auch über den GC-Gehalt des Produktes Auskunft.

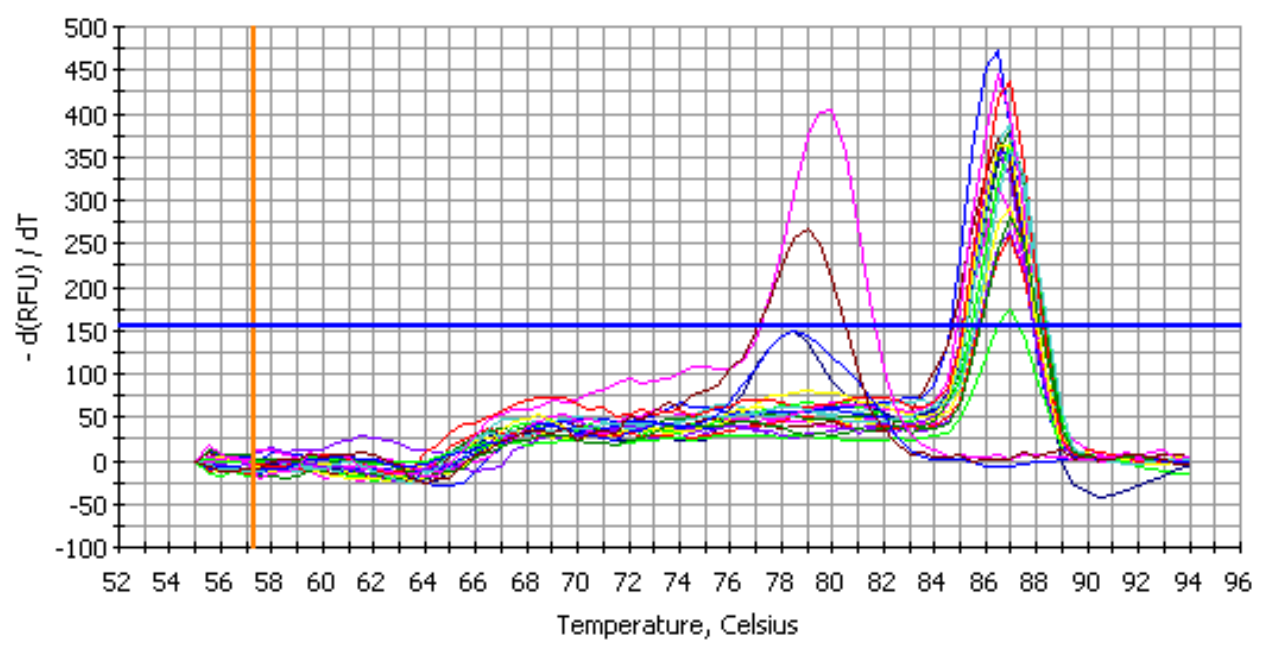

Abb. 2.5: Repräsentatives Bild einer Schmelzpunktanalyse, hier für PBGD. Die Peaks zwischen $78-80^{\circ} \mathrm{C}$ zeigen falsch amplifizierte Produkte in den Le erproben ohne cDNA, der Schmelzpunkt für PBGD liegt bei $86,5^{\circ} \mathrm{C}$ bzw. $87,0^{\circ} \mathrm{C}$. 


\subsection{Statistische Auswertung der Ergebnisse}

Aus den während der PCR gemessenen Thresholdwerten wurden mittels einer Eichgeraden die Ausgangskonzentrationen der einzelnen Gene bestimmt. Alle Werte sind angegeben in Attomol / $\mu \mathrm{g}$ tcRNA als Mittelwert \pm Standardabweichung. Für den Vergleich untereinander bzw. zur Feststellung von Unterschieden zwischen den Gruppen (Hydronephrose $\leftrightarrow$ Kontralateral, Hydronephrose $\leftrightarrow$ Kontrolle, Kontralateral $\leftrightarrow$ Kontrolle) wurden pro Gen und Pool drei Messungen vorgenommen.

Es wurde eine Ein-Faktor-Varianzanalyse durchgeführt, gefolgt vom Scheffes-Test. Die statistische Signifikanz wurde definiert als $p<0.01$ bzw. $p<0.05$. 


\section{Ergebnisse}

\subsection{Messverfahren}

Die Expression der mRNA der einzelnen untersuchten Gene wurde mittels real-time RT-PCR gemessen und wird präsentiert als Mittelwert \pm Standardabweichung der mRNA-Konzentration in Attomol $/ \mu \mathrm{g}$ tcRNA. Die isolierte mRNA der einzelnen Nieren wurde gepoolt, die Anzahl an Proben für die 14 Tage alten Tiere betrug für die obstruierten Nieren $n=5$, für die kontralateralen Nieren $n=3$ und in der Kontrollgruppe $n=6$. Bei den 32 Tage alten Tieren betrug die Anzahl der Proben für die obstruierten Nieren $n=16$, für die kontralateralen Nieren $n=10$ und in der Kontrollgruppe $n=4$. Es wurde pro Gen und Pool in beiden Altersklassen jeweils drei Messungen durchgeführt, deren Mittelwerte und Standardabweichungen ermittelt und miteinander verglichen wurden.

Statistische Signifikanzen wurden definiert als $p<0,05$ bzw. $p<0,01$ und sind in allen folgenden Abbildungen markiert $(*=p<0,05 ; * *=p<0,01)$.

\subsection{Housekeeping-Gen}

Als Housekeeping-Gen, dessen Expression in allen Nieren konstant ist, wurde Porphobilinogen-Desaminase (PBGD) gewählt.

Die mRNA-Konzentration bei den 14 Tage alten Tieren betrug bei den obstruktiven Nieren $173 \pm 12 \mathrm{amol} / \mu \mathrm{gg}$, bei den kontralateralen Nieren $143 \pm 25 \mathrm{amol} / \mathrm{\mu g}$ und in der Kontrollgruppe $140 \pm 17 \mathrm{amol} / \mu \mathrm{g}$. Es sind keine statistisch relevanten Differenzen erkennbar (Abbildung 3.2 A).

PBGD

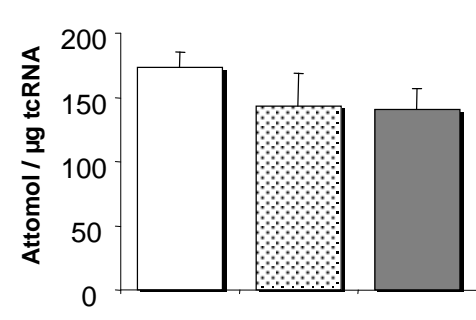

Abb. 3.2 A: Genexpression von PBGD, 14 Tage alte Tiere

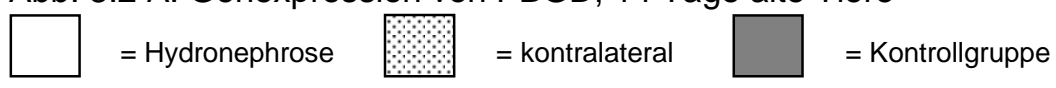


Bei den 32 Tage alten Tieren betrug die mRNA-Konzentration für die obstruktiven Nieren $93 \pm 3 \mathrm{amol} / \mathrm{\mu g}$, für die kontralateralen Nieren $93 \pm 15 \mathrm{amol} / \mathrm{\mu g}$ und in der Kontrollgruppe $87 \pm 35 \mathrm{amol} / \mathrm{\mu g}$. Auch hier sind keine statistisch relevanten Differenzen erkennbar (Abbildung 3.2 B).

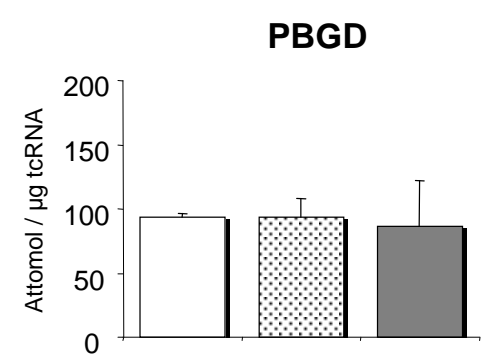

Abb. 3.2 B: Genexpression von PBGD, 32 Tage alte Tiere

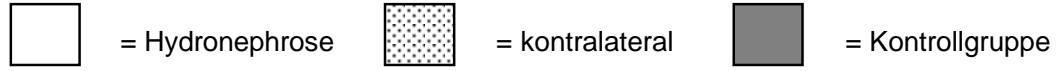

\subsection{Botenstoffe}

Wnts sind Glykoproteine, die für die interzelluläre Signalübertragung verantwortlich sind.

\subsubsection{Wnt 4}

Die Wnt 4-Expression der 14 Tage alten Tiere betrug im Pool Hydronephrose 5,9 \pm $2,5 \mathrm{amol} / \mathrm{\mu g}$, im Pool Kontralateral 10,4 $\pm 2,2 \mathrm{amol} / \mu \mathrm{g}$, im Kontrollpool 10,0 $\pm 2,4$ amol/ $\mu \mathrm{g}$. Für die obstruierten Nieren ist also eine signifikante Erniedrigung in der Expression von Wnt 4 zu erkennen (Abbildung 3.3.1 A).

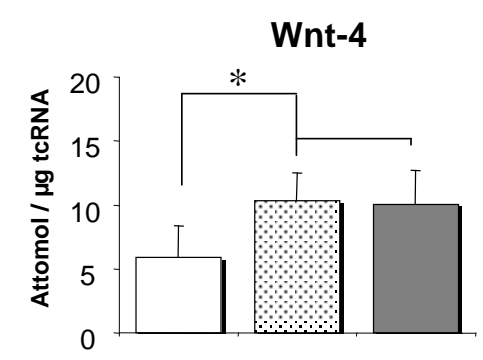

Abb. 3.3.1 A: Genexpression von Wnt-4, 14 Tage alte Tiere 
Bei den 32 Tage alten Tieren betrug die Expression im Pool Hydronephrose 14,0 \pm 4,4 amol/ $\mu \mathrm{g}$, im Pool Kontralateral 1,2 \pm 1,6 amol/ $\mu \mathrm{g}$ und im Kontrollpool 2,8 \pm 2,9 amol/ $\mu \mathrm{g}$. Es ist eine deutliche erhöhte Expression von Wnt 4 in den erkrankten Nieren dieser Versuchsgruppe zu erkennen $(p<0,05$ versus Kontrolle, $p<0,01$ versus Kontralateral) (Abbildung 3.3.1 B).

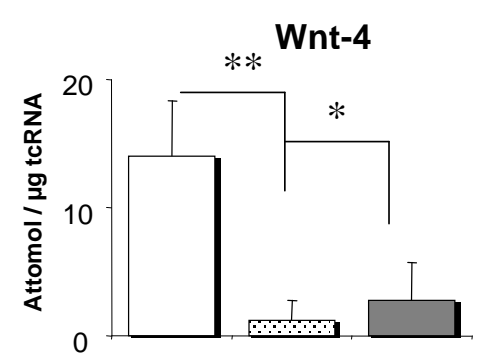

Abb. 3.3.1 B: Genexpression von Wnt-4, 32 Tage alte Tiere

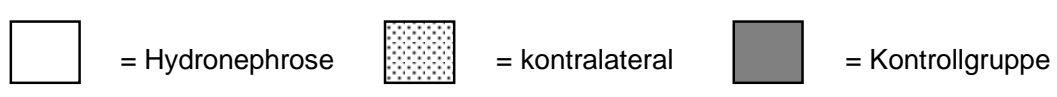

\subsubsection{Wnt 7b}

Bei den 14tägigen Tieren wurden folgende Werte für die Expression von Wnt $7 \mathrm{~b}$ gemessen: Pool Hydronephrose 2,4 \pm 0,7 amol/ $\mu$ g, Pool Kontralateral 2,3 $\pm 0,6$ amol/ $\mu \mathrm{g}$, Kontrollpool 3,3 $\pm 1,4 \mathrm{amol} / \mu \mathrm{g}$. Es konnten keine signifikanten Unterschiede festgestellt werden (Abbildung 3.3.2 A).

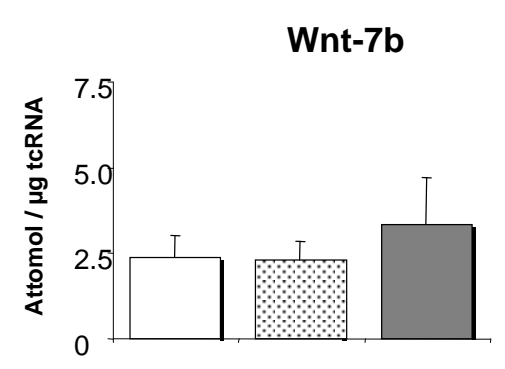

Abb. 3.3.2 A: Genexpression von Wnt-7b, 14 Tage alte Tiere
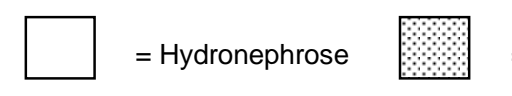

$=$ kontralateral

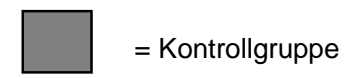

Die Ergebnisse bei den 32 Tage alten Tieren betrugen im Pool Hydronephrose 1,3 \pm $0,3 \mathrm{amol} / \mu \mathrm{g}$, im Pool Kontralateral 0,5 $\pm 0,3 \mathrm{amol} / \mu \mathrm{g}$ und für den Kotrollpool 0,2 $\pm 0,1$ amol $/ \mu \mathrm{g}$. Gegenüber Kontrollgruppe und Kontralateral ist die Expression von Wnt $7 \mathrm{~b}$ in den obstruierten Nieren signifikant erhöht $(p<0,01$ bzw. $p<0,05)$ (Abb. 3.2.2 B). 


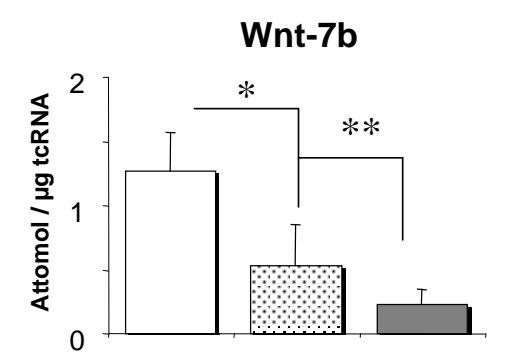

Abb. 3.2.2 B: Genexpression von Wnt-7b, 32 Tage alte Tiere

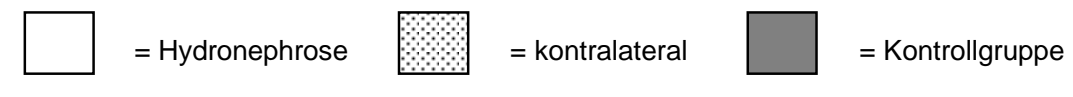

\subsection{Rezeptoren}

Die Signalübermittlung der Wnts wird durch ihre spezifischen Rezeptoren, genannt Frizzled, gewährleistet (Huelsken und Behrens 2002; Strutt 2003).

\subsubsection{Frizzled 1}

Die Expression von Frizzled 1 bei den 14tägigen Tieren betrug im Pool Hydronephrose 2,3 $\pm 0,8 \mathrm{amol} / \mathrm{\mu g}$, im Pool Kontralateral 2,6 $\pm 1,1 \mathrm{amol} / \mu \mathrm{g}$ und im Pool Kontrolle 1,6 $\pm 0,6 \mathrm{amol} / \mu \mathrm{g}$. Es fanden sich keine signifikanten Unterschiede (Abbildung 3.4.1 A).

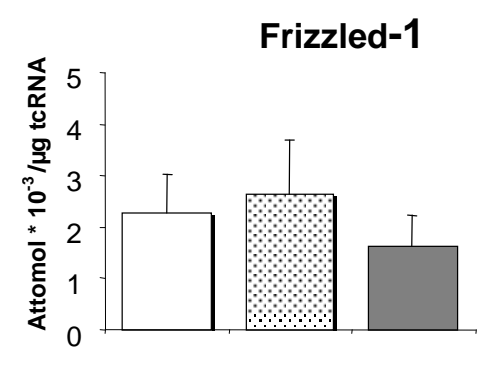

Abb. 3.4.1 A: Genexpression von Frizzled-1, 14 Tage alte Tiere

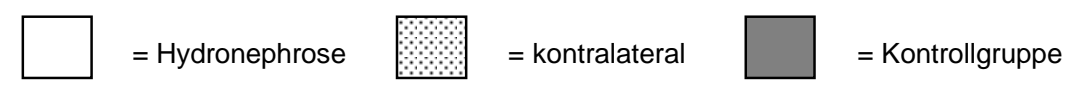

Bei den 32 Tage alten Tieren betrugen die Werte für den Pool Hydronephrose 1,6 \pm $0,8 \mathrm{amol} / \mu \mathrm{g}$, für den Pool Kontralateral 2,1 $\pm 1,6 \mathrm{amol} / \mu \mathrm{g}$ und für den Kontrollpool 0,7 $\pm 0,6 \mathrm{amol} / \mu \mathrm{g}$. Es finden sich keine signifikanten Unterschiede (Abbildung 3.4.1 B). 


\section{Frizzled-1}

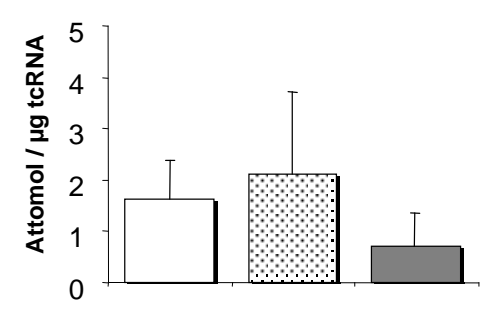

Abb. 3.4.1 B: Genexpression von Frizzled-1, 32 Tage alte Tiere

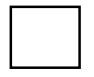

= Hydronephrose

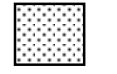

$=$ kontralateral

$=$ Kontrollgruppe

\subsubsection{Frizzled 2}

Die Expression bei den 14tägigen Tieren betrug im Pool Hydronephrose 12,4 \pm 4,9 amol/ $\mathrm{\mu g}$, im Pool Kontralateral 10,8 $\pm 1,8 \mathrm{amol} / \mathrm{\mu g}$ und im Kontrollpool 22,1 $\pm 8,7$ amol/ $\mu$; signifikante Unterschiede lagen nicht vor (Abbildung 3.4.2 A).

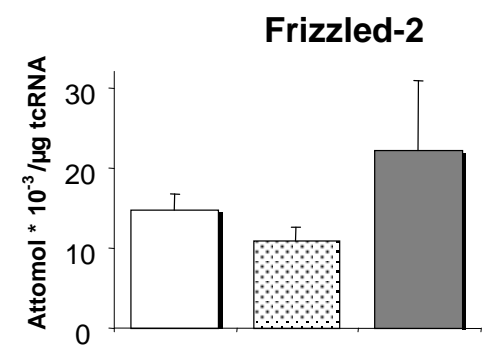

Abb. 3.4.2 A: Genexpression von Frizzled-2, 14 Tage alte Tiere

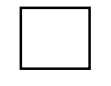

$=$ Hydronephrose

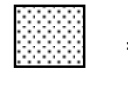

$=$ kontralateral

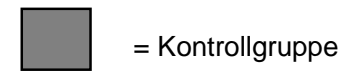

Bei den 32tägigen Tieren betrug die Expression im Pool Hydronephrose 7,2 \pm 05 amol/ $\mu \mathrm{g}$, im Pool Kontralateral 1,1 $\pm 0,2 \mathrm{amol} / \mu \mathrm{g}$ und im Kontrollpool mit $0,7 \pm 0,2$ amol/ $\mu \mathrm{g}$. Es ist eine deutlich erhöhte Expression von Frizzled 2 im Pool Hydronephrose zu erkennen $(p<0,01)$ (Abbildung 3.4.2 B). 


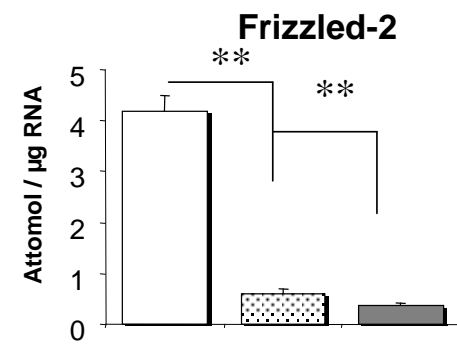

Abb. 3.4.2 B: Genexpression von Frizzled-2, 32 Tage alte Tiere

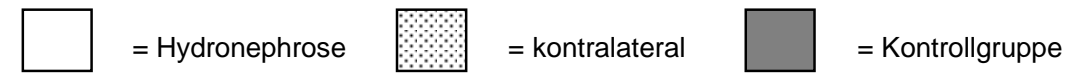

\subsection{Inhibitoren / Antagonisten}

Die Wnt-Signalkette wird hauptsächlich von der Anwesenheit spezifischer Antagonisten beeinflusst. Hierzu gehört der Wnt-Inhibiting factor (WIF) sowie sog. secreted Frizzled-related Proteins (sFRP) (Kawano und Krypta 2003).

\subsection{1 sFRP-1}

Bei den 14 Tage alten Tieren wurden im Pool Hydronephrose $1540 \pm 403,2 \mathrm{amol} / \mathrm{\mu g}$ gemessen, im Pool Kontralateral 586,7 $\pm 23,1 \mathrm{amol} / \mu \mathrm{g}$ und im Kontrollpool 517,7 \pm $142,6 \mathrm{amol} / \mathrm{\mu g}$. Es liegt eine signifikant erhöhte Expression von sFRP-1 in den erkrankten Nieren vor $(p<0,01)$ (Abbildung 3.5.1 A).

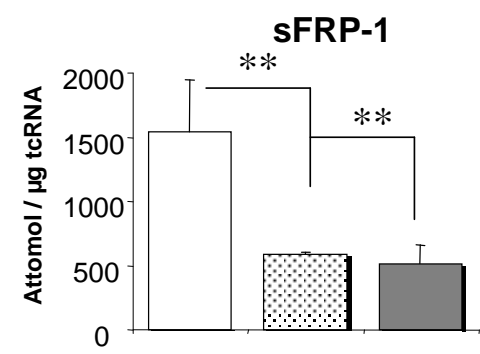

Abb. 3.5.1 A: Genexpression von sFRP-1, 14 Tage alte Tiere

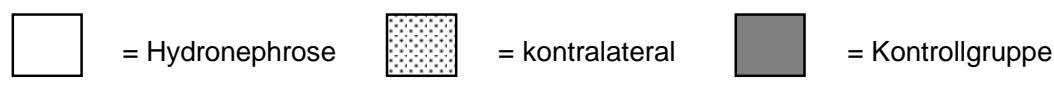

Bei den 32 Tage alten Tieren betrug die Expression im Pool Hydronephrose 863,3 \pm 135,3 amol/ $\mathrm{\mu g}$, im Pool Kontralateral 241,0 \pm 42,5 amol/ $\mu \mathrm{g}$ und im Kontrollpool 230,5 
$\pm 69,1 \mathrm{amol} / \mu \mathrm{g}$. Es ist eine deutlich erhöhte Expression von sFRP-1 in den erkrankten Nieren zu erkennen $(p<0,01)$ (Abbildung 3.5.1 B).

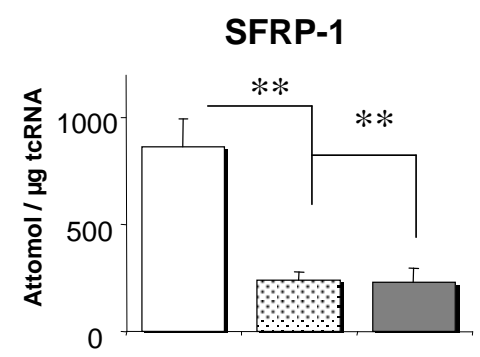

Abb. 3.5.1 B: Genexpression von sFRP-1, 32 Tage alte Tiere<smiles>C1CCC1</smiles>
$=$ Hydronephrose

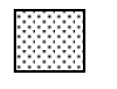
$=$ kontralateral = Kontrollgruppe

\subsection{2 sFRP-2}

Die Expression von sFRP-2 bei den 14tägigen Tieren betrug im Pool Hydronephrose $1333 \pm 451 \mathrm{amol} / \mathrm{\mu g}$, im Pool Kontralateral $397 \pm 29 \mathrm{amol} / \mu \mathrm{g}$ und im Kontrollpool 640 $\pm 69 \mathrm{amol} / \mathrm{\mu g}$. Die Expression von sFRP-2 ist in den obstruierten Nieren im Vergleich zu den kontralateralen Nieren sowie zur Kontrollgruppe signifikant erhöht $(p<0,05)$ (Abbildung 3.5.2 A).

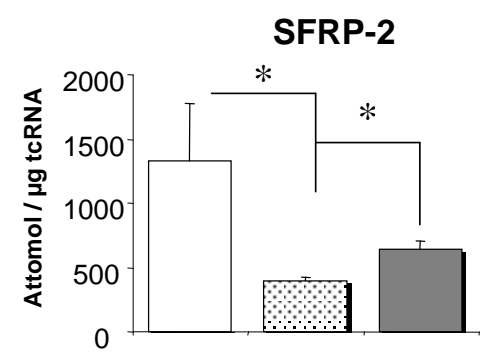

Abb. 3.5.2 A: Genexpression von sFRP-2, 14 Tage alte Tiere

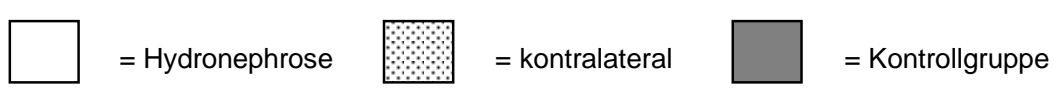

Bei den 32tägigen Tieren betrug die Expression im Pool Hydronephrose 216,7 $\pm 28,9$ amol/ $\mathrm{\mu g}$, im Kontralateralpool 246,7 $\pm 45,1 \mathrm{amol} / \mu \mathrm{g}$ und im Kontrollpool 393,3 \pm $149,8 \mathrm{amol} / \mathrm{\mu g}$. Untereinander zeigten die einzelnen Pools keine signifikanten Unterschiede in der Expressionsrate für sFRP-2 (Abbildung 3.5.2 B). 


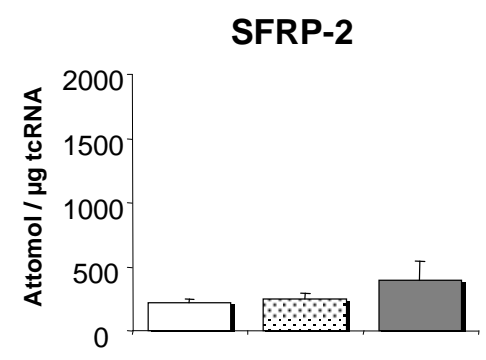

Abb. 3.5.2 B: Genexpression von sFRP-2, 32 Tage alte Tiere

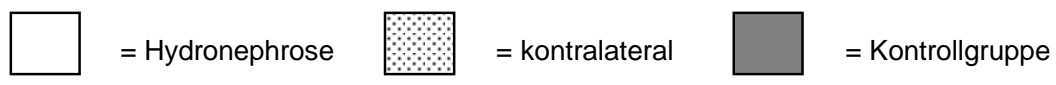

\subsubsection{WIF-1}

Die Expression von WIF-1 betrug bei den 14 Tage alten Tieren im Pool Hydronephrose 19,0 \pm 5,6 amol/ $\mathrm{gg}$, im Pool Kontralateral 16,7 $\pm 5,9 \mathrm{amol} / \mathrm{\mu g}$ und $\mathrm{im}$ Pool Kontrolle 13,7 $\pm 2,3 \mathrm{amol} / \mathrm{\mu g}$. Es konnten keine signifikanten Unterschiede nachgewiesen werden (Abbildung 3.5.3 A).

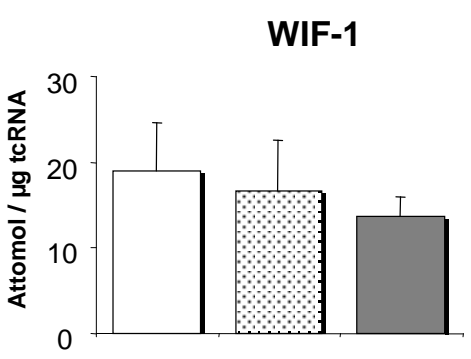

Abb. 3.5.3 A: Genexpression von WIF-1, 14 Tage alte Tiere

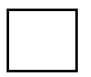

$=$ Hydronephrose

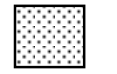

$=$ kontralateral

$=$ Kontrollgruppe

Bei den 32 Tage alten Tieren betrug die Expression von WIF-1 im Pool Hydronephrose 8,7 $\pm 1,5 \mathrm{amol} / \mathrm{\mu g}$, im Pool Kontralateral 2,7 $\pm 1,5 \mathrm{amol} / \mathrm{\mu g}$ und $\mathrm{im}$ Pool Kontrolle 1,5 $\pm 0,4 \mathrm{amol} / \mathrm{\mu g}$. Es konnte eine deutliche erhöhte Genexpression in den erkrankten Nieren nachgewiesen werden $(p<0,01$ gegenüber Kontralateral und Kontrolle) (Abbildung 3.5.3 B). 


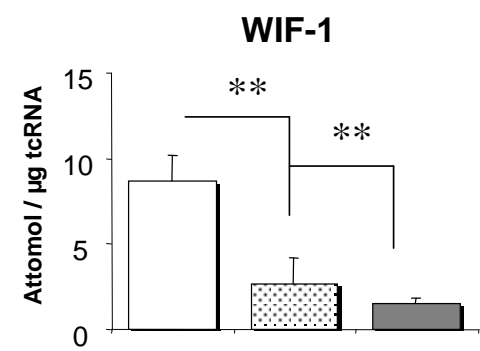

Abb. 3.5.3 B: Genexpression von WIF-1, 32 Tage alte Tiere

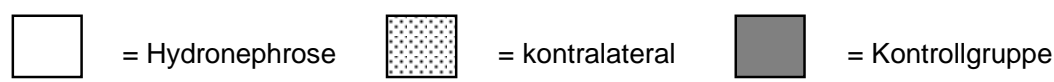

\subsection{Gene der Signalketten}

Die Signalübertragung der Wnts erfolgt auf drei verschiedenen Wegen: dem BCatenin oder auch kanonischen Weg, dem Weg der planaren Zellpolarität, welcher auch die jun-N-terminale Kinase (JNK) beinhaltet sowie dem Wnt $/ \mathrm{Ca}^{2+}$-Signalweg, der Calcineurin mit einschließt (Miller 2001; Huelsken und Behrens 2002).

\subsubsection{JNK}

Die Expression von JNK bei den 14tägigen Tieren betrug im Pool Hydronephrose 6,3 $\pm 2,0 \mathrm{amol} / \mathrm{\mu g}$, im Pool Kontralateral 2,8 $\pm 0,4 \mathrm{amol} / \mu \mathrm{g}$ und im Kontrollpool 2,2 \pm 0,6 $\mathrm{amol} / \mu \mathrm{g}$ gemessen. Die JNK-Expression in obstruierten Nieren war signifikant erhöht im Vergleich zur Kontrollgruppe und zu den kontralateralen Nieren $(p<0,01)$ (Abbildung 3.6.1 A).

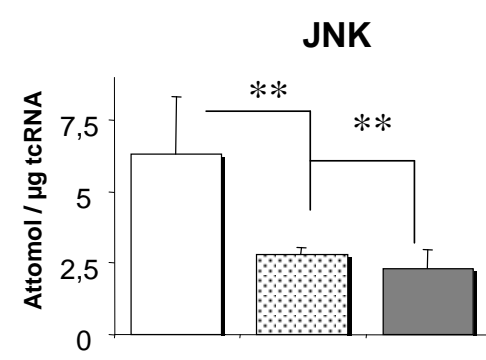

Abb. 3.6.1 A: Genexpression von JNK, 14 tage alte Tiere

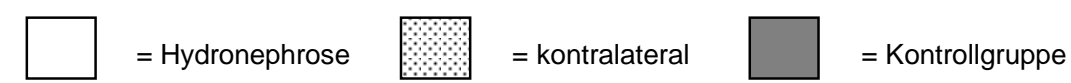


Die Expression bei den 32 Tage alten Tieren betrug im Pool Hydronephrose 1,8 \pm 0,7 $\mathrm{amol} / \mu \mathrm{g}$ gemessen, im Pool Kontralateral 1,3 $\pm 0,5 \mathrm{amol} / \mu \mathrm{g}$ und $\mathrm{im}$ Kontrollpool 3,3 \pm $0,8 \mathrm{amol} / \mathrm{\mu g}$. Es zeigten sich keine signifikanten Unterschiede (Abbildung 3.6.1 B).

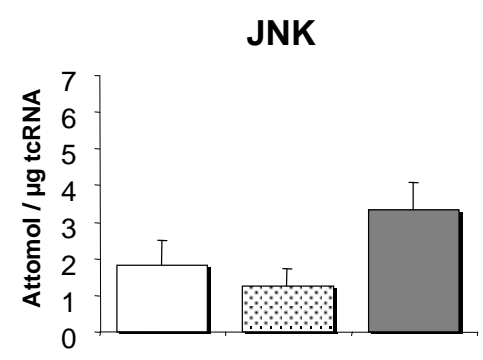

Abb. 3.6.1 B: Genexpression von JNK, 32 Tage alte Tiere

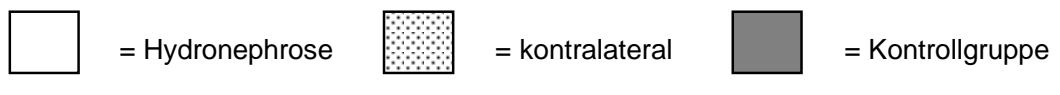

\subsubsection{Calcineurin}

Die Expression von Calcineurin bei den 14-tägigen Tieren betrug für den Pool Hydronephrose $1733,7 \pm 289,1 \mathrm{amol} / \mu \mathrm{g}$, für den Pool Kontralateral 1249,3 $\pm 412,9$ amol/ $\mu \mathrm{g}$ und für den Kontrollpool 696,7 $\pm 28,9 \mathrm{amol} / \mu \mathrm{g}$. Es zeigte sich eine dezente Erhöhung der Expression von Calcineurin in den hydronephrotischen Nieren gegenüber der Kontrolle $(p<0,05)$ (Abbildung 3.6.2 A).

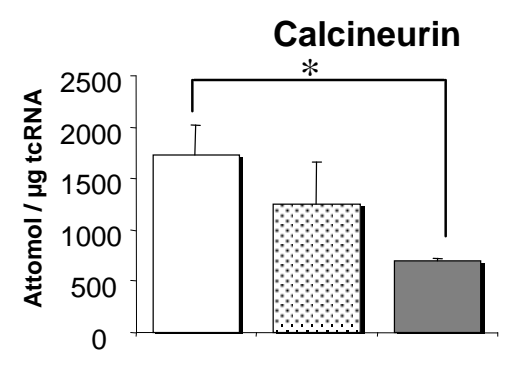

Abb. 3.6.2 A: Genexpression von Calcineurin, 14 Tage alte Tiere
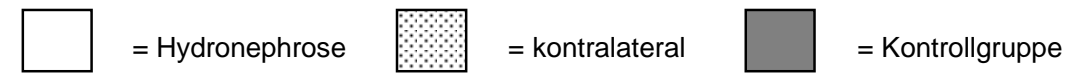

Bei den 32 Tage alten Tieren betrug die Expression im Pool Hydronephrose 623,3 \pm $146,4 \mathrm{amol} / \mu \mathrm{gg}$, im Pool Kontralateral 334,0 $\pm 154,0 \mathrm{amol} / \mu \mathrm{g}$ und im Kontrollpool 
$996,7 \pm 459,4 \mathrm{amol} / \mu \mathrm{gg}$. Ein statistisch relevanter Unterschied konnte nicht nachgewiesen werden (Abbildung 3.6.2 B).

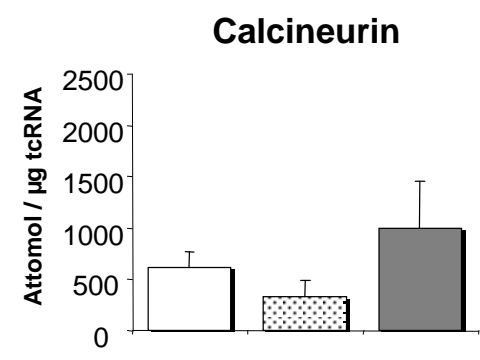

Abb. 3.6.2 B: Genexpression von Calcineurin, 32 Tage alte Tiere

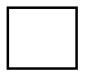

$=$ Hydronephrose

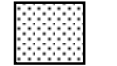

$=$ kontralateral

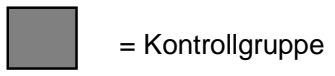

\subsubsection{B-Catenin}

Die Expression von B-Catenin betrug bei den 14 Tage alten Tieren im Pool Hydronephrose $659,3 \pm 110,9 \mathrm{amol} / \mu \mathrm{g}$, im Kontralateralpool 203,7 $\pm 7,5 \mathrm{amol} / \mu \mathrm{g}$ und im Kontrollpool 283,7 $\pm 72,7 \mathrm{amol} / \mathrm{\mu g}$.

Die Expression von B-Catenin war in den erkrankten Nieren sowohl gegenüber der Kontrollgruppe als auch den gesunden kontralateralen Nieren signifikant erhöht $(p<0,01)$ (Abbildung 3.6.3 A).

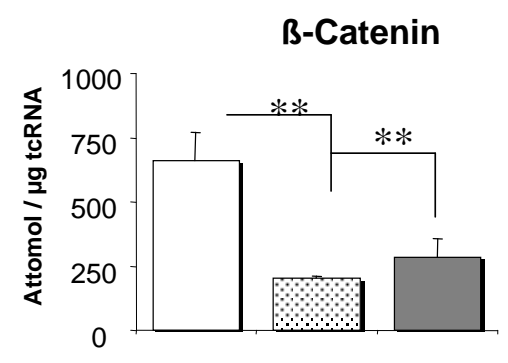

Abb. 3.6.3 A: Genexpression von B-Catenin, 14 Tage alte Tiere

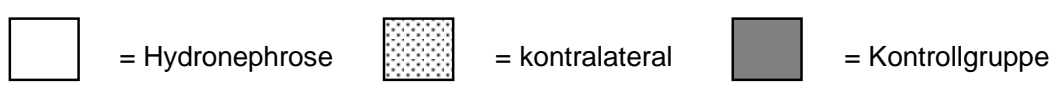

Bei den 32tägigen Tiere betrug die Expression im Pool Hydronephrose 266,7 \pm 202,6 $\mathrm{amol} / \mathrm{\mu g}$, im Pool Kontralateral 218,0 $\pm 21,3 \mathrm{amol} / \mathrm{\mu g}$ und im Kontrollpool 292,7 \pm $108,0 \mathrm{amol} / \mathrm{\mu g}$. Es liegen keine signifikanten Unterschiede vor (Abbildung 3.6.3 B). 


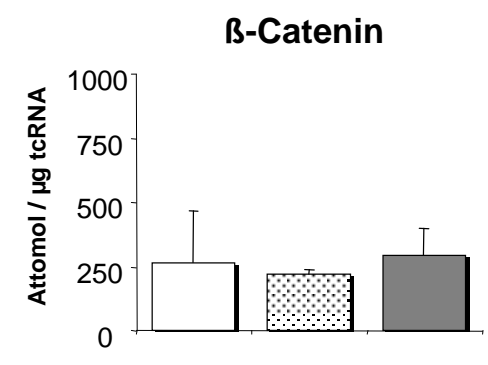

Abb. 3.6.3 B: Genexpression von B-Catenin, 32 Tage alte Tiere

$=$ Hydronephrose
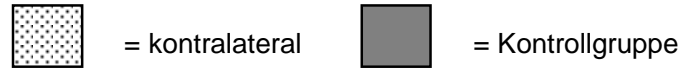

\subsection{TGF-ß1}

Die Expression von TGF- $\beta 1$ bei den 14 Tage alten Tiere betrug im Pool Hydronephrose 17,8 \pm 6,6 amol$/ \mu \mathrm{gg}$, im Pool Kontralateral 77,0 $\pm 15,3 \mathrm{amol} / \mathrm{\mu g}$ und $\mathrm{im}$ Kontrollpool 115,4 $\pm 29,5 \mathrm{amol} / \mathrm{\mu g}$. Eine Herabregulierung der Genexpression in den erkrankten Nieren wird im Vergleich zur Gegenseite und besonders im Vergleich zur Kontrollgruppe deutlich ( $p<0,05$ bzw. $p<0,01$ ) (Abbildung $3.7 \mathrm{~A}$ ).

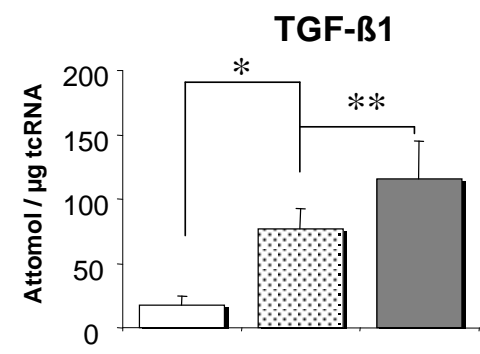

Abb. 3.7 A: Genexpression von TGF-B1, 14 Tage alte Tiere

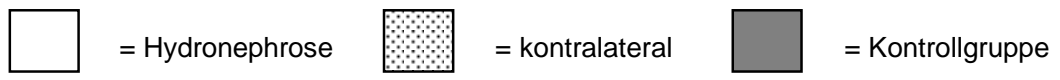

Die RNA-Expression von TGF- $B 1$ bei den 32Tage alten Ratten wurde bereits untersucht (Seseke et al. 2004). Bei den obstruierten Nieren fand sich eine mRNAKonzentration für TGF-B1 von 4,5 \pm 0,4 amol/ $\mu \mathrm{g}$, für die kontralateralen Nieren 1,2 \pm $0,1 \mathrm{amol} / \mu \mathrm{g}$ sowie in der Kontrollgruppe $1,3 \pm 0,2 \mathrm{amol} / \mu \mathrm{gg}$. 
Es wurde eine signifikante Erhöhung der Expression in den erkrankten Nieren mit Hydronephrose nachgewiesen (Abbildung 3.7 B).

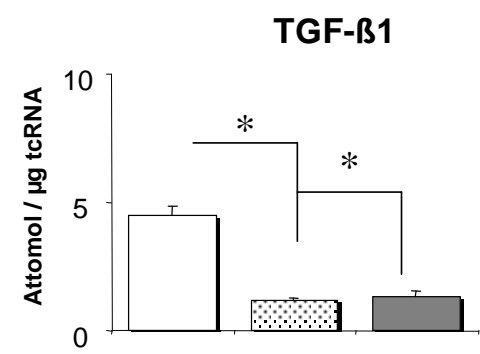

Abb. 3.7 B: Genexpression von TGF-ß1, 32 Tage alte Tiere

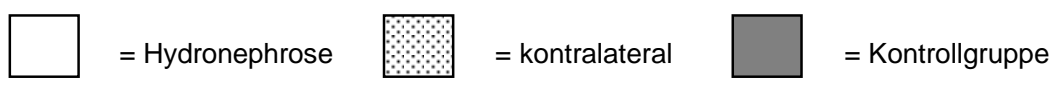




\section{Diskussion}

Die Wnt-Signalkette spielt eine wichtige Rolle in der normal verlaufenden Nephrogenese (Vaino 2003). Die kongenitale renale Obstruktion beeinflusst maßgeblich die Phase der Metanephrogenese, besonders der Tubulogenese (Chevalier et al. 1987; Chevalier 1995; Chevalier 1999; Klahr 2001; Seseke et al. 2001). Allerdings ist die Rolle der Wnts - bezogen auf diese speziellen pathophysiologischen Abläufe - nur sehr sporadisch untersucht und ihre genauen Funktionen sind in diesem Zusammenhang zum Großteil noch unbekannt. Bis heute gibt es nur eine tierexperimentelle Arbeit an Ratten, die sich mit der Rolle des WntSignalsystems im Kontext mit einer experimentellen renalen Obstruktion in der Entwicklungsphase der Niere beschäftigt (Nguyen et al. 1999).

In der vorgelegten Arbeit war es möglich, den Einfluss von Wnts, ihrer Rezeptoren sowie ihrer Inhibitoren erstmals auch auf die sich spontan entwickelnde kongenitale obstruktive Uropathie der Ratte darzustellen.

\subsection{Wnts}

Wnt-4 ist eines der Schlüsselenzyme der Wnt-Signalkette in der physiologischen Nephrogenese. Es reguliert die Kommunikation zwischen Ureterknospe und metanephrogenetischem Blastem in frühen Stadien der Metanephrogenese. In späteren Stadien wirkt es hauptsächlich auf die normale Entwicklung des Tubulussystems (Kispert et al. 1998; Vaino und Uusitalo 2000; Vaino 2003).

Im Gegensatz zum Menschen findet bei Ratten ein Großteil der Nephrogenese erst postpartal statt und endet etwa 14 Tage post partum (Merlet-Benichou et al. 1994). Bei der Untersuchung von Nieren 14 Tage alter Ratten mit kongenitaler Obstruktion war eine erniedrigte Genexpression von Wnt-4 zu beobachten (Abb. 3.3.1 A), während bei Ratten des Alters von 32 Tagen - also nach Abschluss der Nephrogenese - ein deutlicher Anstieg der Wnt-4-Genexpression zu verzeichnen war (Abb. 3.3.1 B).

Bei gesunden Rattennieren kommt es nach Abschluss der Nephrogenese ohne Verzögerung zu einem Abfall der Genexpression von Wnt-4 (Nguyen et al. 1999) Nguyen et al. demonstrierten an der Ratte, dass eine komplette Obstruktion der 
Ureteren bei neugeborenen Tieren eine über den Zeitraum der Nephrogenese hinaus andauernde Erhöhung des Wnt-4-Spiegels zur Folge hat. Des Weiteren führte eine Unterbindung der Ureteren nach Abschluss der Nephrogenese zu einer Reaktivierung der Wnt-4 Genexpression (Nguyen et al. 1999).

Die eigenen Ergebnisse in der Phase der Nephrogenese stehen somit teilweise im Gegensatz zu den Ergebnissen von Nguyen et al., was höchstwahrscheinlich auf Unterschiede in den verwendeten Tiermodellen zurückzuführen ist. In dem hier genutzten Modell entwickelt sich die angeborene renale Obstruktion spontan, außerdem kommt es nur zu einer partiellen Obstruktion (Seseke et al. 2000). Die beobachtete Abnahme der Wnt-4 Genexpression bei den 14 Tage alten Tieren kann somit am ehesten auf eine Hemmung der Nephrogenese bei kongenital aufgetretener renaler Obstruktion zurückgeführt werden.

Offensichtlich spielt Wnt-4 ebenfalls eine Rolle bei Heilungsprozessen renaler Verletzungen (Surendran et al. 2002; Terada et al. 2003). Die im Modell von Nguyen et al. durch Unterbindung des Ureters herbeigeführte komplette Obstruktion (Nguyen et al. 1999) führt letztlich zu einem akuten Nierenversagen der betroffenen Niere. Dieses könnte eine Erklärung für den über den Abschluss der Nephrogenese andauernden, erhöhten Wnt-4-Spiegel im genutzten Modell sein.

Der beobachtete Anstieg der Wnt-4 Genexpression bei den 32 Tage alten Tieren in der eigenen Arbeit wiederum stützt die Ergebnisse von Nguyen et al., da eine länger andauernde partielle renale Obstruktion ebenfalls zu einer signifikanten Schädigung der Niere führt. Morphologisches Zeichen dieser Schädigung ist die Entstehung einer interstitiellen Fibrose, die bei den betroffenen Nieren nachgewiesen werden konnte und zu den charakteristischen morphologischen Merkmalen einer chronischen obstruktiven Uropathie zählt (Seseke et al. 2000; Seseke et al. 2004).

Wnt-4 ist unmittelbar beteiligt am Entwicklungsprozess der Entstehung der interstitiellen Fibrose der Niere (Surendran et al. 2002). Das lässt vermuten, dass der Wnt-4-Anstieg bei den 32-tägigen Tieren mit der fortschreitenden Entwicklung einer interstitiellen Fibrose korreliert. Dies wird zusätzlich durch die Tatsache unterstützt, dass sich parallel auch ein Anstieg der Genexpression von TGF-B1 (Seseke et al. 2000), einem spezifischen molekularen Marker für die Entwicklung der interstitiellen Fibrose der Niere, beobachten ließ (Abb. 3.7 B).

Interessant ist in diesem Zusammenhang, dass bei den 14 Tage alten Tieren ein Abfall der TGF-ß1-Genexpression analog zu den erniedrigten Werten für Wnt-4 
beobachtet wurde (Abb. 3.7 A), was sich ebenfalls durch eine Beeinträchtigung in der Nephrogenese erklären lässt, da TGF-B1 in die normale Nephrogenese involviert ist (Seseke et al. 2001).

Die Bedeutung von Wnt-7b im Zusammenhang mit der kongenitalen obstruktiven Uropathie bleibt unklar. Es fanden sich keine Unterschiede in der Genexpression zwischen betroffenen und gesunden Nieren bei den 14 Tage alten Versuchstieren, also am Ende der Nephrogenese (Abb. 3.3.2 A). Allerdings war die Expression von Wnt-7b in betroffenen Nieren bei anhaltender renaler Obstruktion erhöht (Abb. 3.3.2 B). Wnt-7b spielt eine Rolle bei chronisch-entzündlichen Gelenkserkrankungen (Nakamura et al. 2005). Die Beteiligung von Wnt-7b an der Pathophysiologie der interstitiellen Fibrose wäre folglich eine plausible Erklärung für dieses Phänomen, die jedoch im Rahmen weiterer Untersuchungen untermauert werden müsste .

\subsection{Wnt-Rezeptoren}

Die Signalübermittlung der Wnts wird durch ihre spezifischen Rezeptoren, genannt Frizzled, gewährleistet (Huelsken und Behrens 2002; Strutt 2003). Um die genaue Funktion der Wnt-Signalkette bezüglich der Pathophysiologie der kongenitalen obstruktiven Uropathie zu verstehen, ist es daher erheblich von Bedeutung, ob auch die genetische Expression dieser Rezeptoren charakteristischen Veränderungen unterliegt. Da bisher keine Daten zu Frizzled im Zusammenhang mit der kongenitalen obstruktiven Uropathie vorliegen, beschränkt sich diese Arbeit auf die Untersuchung von Frizzled-1 (friz-1) und Frizzled-2 (friz-2).

Es konnten weder bei den 14 Tage alten noch bei den älteren Tieren Unterschiede in der Genexpression für friz-1 zwischen erkrankten Nieren, den gesunden Nieren der Gegenseite sowie den Nieren der Kontrollgruppe gefunden werden (Abb. 3.4.1 A und 3.4.1 B). Offensichtlich spielt friz-1 in der Pathophysiologie der kongenitalen obstruktiven Uropathie der Ratte keine wesentliche Rolle.

Im Gegensatz dazu fand sich eine signifikant erhöhte Genexpression für friz-2 in den Nieren der älteren Tiere mit länger anhaltender Obstruktion, während bei den jüngeren Tieren zum Ende der Nephrogenese keine unterschiedliche Expression festgestellt werden konnte (Abb. 3.4.2 A und 3.4.2 B). Vaino und Uusitalo 
postulieren, dass friz-2 als spezifischer Rezeptor für Wnt-4 eine Rolle im Rahmen der Steuerung der Tubulogenese spielt (Vaino und Uusitalo 2000). Die Expressionsrate von friz-2 korrelierte jedoch nicht wie vermutet mit der erniedrigten Expressionsrate von Wnt-4 bei obstruierten Nieren der 14 Tage alten Ratten, so dass im Kontext mit der obstruktiven Uropathie in unserem Modell friz-2 zumindest in der Phase der Nephrogenese keine eigenständige Rolle zu spielen scheint.

Im Gegensatz dazu zeigten die hier vorliegenden Ergebnisse nach Abschluss der Nephrogenese eine Korrelation der Expressionswerte von friz-2 mit denen von Wnt4. Daraus lässt sich ableiten, dass der durch den beobachteten Anstieg der Expression vermutete Einfluss von Wnt-4 auf die Entwicklung der interstitiellen Fibrose durch die vermehrte Aktivität seines spezifischen Rezeptors friz-2 zusätzlich gesteigert wird. Friz-2 trägt dadurch offensichtlich ganz wesentlich zur Entwicklung einer chronischen, kongenitalen obstruktiven Uropathie bei.

\subsection{Antagonisten}

Die Wnt-Signalkette wird maßgeblich durch die Aktivität spezifischer Antagonisten beeinflusst, welche in zwei funktionelle Klassen unterteilt werden können: Die secreted Frizzled-related proteins (sFRP) und die Proteine der Dickkopf-Klasse (Kawano und Krypta 2003). Besonders die sFRPs sind an der Regulation der metanephrogenetischen Entwicklung beteiligt (Yoshino et al. 2001). sFRPs, aber auch der Wnt-Inhibitory factor 1 (WIF-1), ein weiterer Antagonist der Wnt-Signalkette, beeinflussen die Aktivität von Wnts, indem sie direkt an diese binden (Yoshino et al. 2001; Kawano und Krypta 2003) und somit ihre Bindungsfähigkeit an den entsprechenden Rezeptor verringern. Ihre Rolle in der Pathophysiologie der obstruktiven Uropathie wurde bisher nicht untersucht.

In der vorliegenden Arbeit wurden die Unterschiede in der Genregulation von sFRP1, sFRP-2 und WIF-1 zwischen obstruktiven, kontralateralen sowie gesunden Rattennieren als Kontrollgruppe untersucht. Wiederum konnten unterschiedliche Expressionsmuster bei den jungen Tieren gegen Ende der Nephrogenese im Vergleich zu den älteren Tieren mit länger andauernder Obstruktion festgestellt werden. Bei den 14 Tage alten Tieren war die Genexpression für sFRP-1 und sFRP2 bei den obstruierten Nieren erhöht, wohingegen sich die Werte für WIF-1 nicht 
unterschieden (Abb. 3.5.1 A; 3.5.2 A; 3.5.3 A). Im Gegensatz dazu fand sich bei den 32 Tage alten Tieren eine gesteigerte Genexpression für WIF-1 sowie sFRP-1, während für sFRP-2 keine Änderungen zu verzeichnen waren (Abb. 3.5.1 B; 3.5.2 B; 3.5.3 B).

In der metanephrogenetischen Entwicklung hemmt sFRP-1 die Verzweigung der Ureterknospen und damit die normale Ausbildung des Tubulussystems. sFRP-2 auf der anderen Seite hat keinen direkten Einfluss auf die Tubulogenese, aber möglicherweise einen antagonistischen Effekt auf sFRP-1 (Yoshino et al. 2001). In Verbindung mit einer erniedrigten Expression von Wnt-4 lässt eine Überexpression von sFRP-1 bei den 14 Tage alten Tieren eine Beeinträchtigung der Tubulogenese vermuten, was wiederum maßgeblich zur Entstehung einer kongenitalen obstruktiven Uropathie beiträgt. Die gleichzeitig erhöhte Expression von sFRP-2 in diesem Zusammenhang bleibt unklar.

Schwieriger ist die Interpretation der Genexpression von SFRP-1 und WIF-1 bei den 32 Tage alten Versuchstieren. Die gesteigerte Expression von Wnt-4 und seinem Rezeptor friz-2 in obstruktiven Nieren legt eine erhöhte Signaltransduktion in der Wnt-Signalkette nahe, welche sowohl von sFRP-1 als auch von WIF-1 antagonisiert werden könnte. Es ist jedoch beschrieben, dass SFRP-1 unter bestimmten Bedingungen ebenso als Agonist zu Wnt-4 wirken kann (Uren et al. 2000). Außerdem kann sFRP-1 Apoptose induzieren (Kawano und Krypta 2003). Es ist daher denkbar, dass eine Steigerung der Expression von sFRP-1 über das Auslösen von Apoptose zu einer tubulären Atrophie führen kann. Apoptose von Tubuluszellen wiederum ist einer der Hauptgründe für die tubuläre Atrophie bei kongenitaler obstruktiver Uropathie (Chevalier et al. 1996; Chevalier 1999; Klahr 2001). Es ist daher möglich, dass die erhöhte Gen-Expression von sFRP-1 durch die Induktion von Apoptose zur tubulären Atrophie beiträgt.

Die Rolle von WIF-1 in der Pathophysiologie der kongenitalen obstruktiven Uropathie bleibt unklar. Außerdem ist es ungewiss, ob WIF-1 Interaktionen mit Wnt-4 bzw. Wnt7b zeigt oder nicht. Allerdings zeigen aktuelle Arbeiten an Zellkulturen aus kolorektalen oder Prostatakarzinomen, dass eine erhöhte Aktivität von WIF-1 durch Beeinträchtigung der Wnt-Signalkette zu Apoptose führt (He et al. 2005; Ohigashi et al. 2005). Es lässt sich daher vermuten, dass die beobachtete erhöhte Expression von WIF-1 in Nieren mit kongenitaler Obstruktion zu einer erhöhten apoptotischen Aktivität beiträgt. 


\subsection{Die Wnt-Signalketten}

Die Signalübertragung der Wnts erfolgt auf drei verschiedenen Wegen: 1. dem BCatenin- oder auch kanonischen Weg, 2. dem Weg der planaren Zellpolarität, sowie 3. dem Wnt/Ca ${ }^{2+}$-Signalweg (Miller 2001; Huelsken und Behrens 2002).

Die oben erwähnten Ergebnisse bezüglich Wnts, Rezeptoren und Antagonisten legen nahe, dass Wnt-vermittelte Signalübertragung in der Pathophysiologie der kongenitalen obstruktiven Uropathie der Ratte eine Rolle spielt. Es ist allerdings bisher unklar, über welchen der Signalwege die Wnts ihre Informationen weitergeben. Zur Beantwortung dieser Frage fokussierten wir in dieser Arbeit zunächst auf die Schlüssel-Stationen der einzelnen Signalwege: Die Expression von B-Catenin im Hinblick auf den kanonischen Weg, die JNK-Expression bezüglich des Weges der planaren Zellpolarität sowie Calcineurin für den Wnt/Ca ${ }^{2+}$-Signalweg. Weder bei den 14 Tage alten Versuchstieren noch bei den 32 Tage alten Tieren mit chronischer, kongenitaler, renaler Obstruktion konnten Unterschiede in der renalen Genexpression von Calcineurin festgestellt werden (Abb. 3.6.2 A und 3.6.2 B). Demnach ist der $\mathrm{Wnt} / \mathrm{Ca}^{2+}$-Signalweg an der Entwicklung der kongenitalen obstruktiven Uropathie höchstwahrscheinlich nicht beteiligt.

Die Genexpression von JNK war nur bei den obstruierten Nieren der 14 Tage alten Versuchtiere signifikant erhöht (Abb. 3.6.1 A). Dies steht allerdings in Kontrast zu der zu diesem Zeitpunkt verminderten renalen Expression von Wnt-4. Eine mögliche Erklärung hierfür ist ein von der Wnt-Signalübertragung unabhängiges Phänomen, welches eine Steigerung der JNK-Expression verursacht. JNK spielt in der physiologischen Entwicklung der Niere keine Rolle (Awazu et al. 2002). In reifen Nieren jedoch führt es, vor allem aktiviert durch mechanische Belastung der Zelle, zu einer Unterdrückung des zellulären Wachstums und induziert Apoptose (Xia et al. 1995; Awazu et al. 2002). Es liegt nahe, dass der erhöhte hydrostatische Druck im Falle der kongenitalen renalen Obstruktion zu solch zellulärem Stress beiträgt, was eine Aktivierung der renalen Expression von JNK verursachen könnte. Während der Nephrogenese führt dies wiederum zu einem beeinträchtigten Organwachstum, einem typischen morphologischen Parameter der kongenitalen obstruktiven Uropathie. 
Bei den 32 Tage alten Versuchstieren mit länger bestehender, kongenitaler, renaler Obstruktion konnten keine Unterschiede in der Genregulation von JNK festgestellt werden (Abb. 3.6.1 B). Obwohl bei diesen Tieren die Genexpression von Wnt-4, Wnt7b und friz-2 in den obstruktiven Nieren eine deutliche Aktivierung der WntSignalvermittlung vermuten lässt, scheint der Signalweg der planaren Zellpolarität in dieser pathophysiologischen Konstellation keine Rolle zu spielen.

Da weder der Wnt/ $\mathrm{Ca}^{2+}$-Signalweg noch der Weg der planaren Zellpolarität an der Entwicklung der kongenitalen obstruktiven Uropathie beteiligt ist, müssen die WntSignale offensichtlich über den kanonischen Weg vermittelt werden. In diesem Zusammenhang sind nicht unbedingt Änderungen bezüglich der Genexpression von B-Catenin zu erwarten, da die Wnt-Signale durch eine Translokation von intrazellulär verfügbarem B-Catenin zum Nukleus der Zelle übertragen werden (Huelsken und Behrens 2002). Diese Vermutung wird durch die Ergebnisse der B-CateninExpression bei den 32 Tage alten Ratten untermauert (Abb. 3.6.3 B). Weiterhin bestätigen aktuellere Arbeiten, dass die Signalübertragung der Wnt-Signalkette über den kanonischen Weg abläuft (Surendran et al. 2002; He et al. 2005).

Dennoch scheint die Situation im Hinblick auf die 14 Tage alten Tiere mit kongenital obstruierten Nieren offensichtlich abzuweichen. Interessanterweise konnte in den betroffenen Nieren eine deutlich gesteigerte Genexpression für B-Catenin festgestellt werden (Abb. 3.6.3 A). Bei gleichzeitig erniedrigter Expression von Wnt-4 scheint auch dieses Phänomen offensichtlich unabhängig von der Wnt-Signalübertragung zu sein.

Es ist bekannt, dass B-Catenin eine entscheidende Rolle für die Regulation der Zelladhäsion (Nagafuchi et al. 1987; Aberle et al. 1994; Nguyen et al. 1999) und hierdurch auch für die Stabilität des Zytoskeletts spielt. Erhöhter hydrostatischer Druck, wie er bei renaler Obstruktion entsteht, führt zur Aufweitung der epithelialen Zellkontakte insbesondere im Bereich der Nierentubuli (Nguyen et al. 1999). Die Überexpression von B-Catenin bei 14 Tage alten Nieren kann deshalb als eine Art Schutzmechanismus verstanden werden, der zumindest im frühen Stadium der renalen Obstruktion der Instandhaltung von Zellkontakten dient.

Andererseits ist B-Catenin maßgeblich an der durch TGF-B1-induzierten Umwandlung von Epithel zu Myofibroblasten beteiligt, welche letztlich zur Entwicklung der tubulointerstitiellen Fibrose bei Nierenerkrankungen führt (Tian et al. 2003; Masszi et al. 2004). Im Gegensatz zu der bei den älteren Tieren beobachteten 
Steigerung der TGF-ß1-Expression konnte bei den obstruierten Nieren der 14 Tage alten Tiere eine deutlich abgeschwächte Genexpression von TGF-B1 festgestellt werden (Abb. 3.7 A und 3.7 B). Diese Erkenntnis macht synergistische Effekte von BCatenin und TGF-B1 zumindest zum Ende der Nephrogenese unwahrscheinlich, unterstreicht allerdings die Beeinträchtigung der Nephrogenese durch kongenitale renale Obstruktion, da das TGF-B1-Signalsystem entscheidend für die normale Entwicklung der Niere ist (Vrljicak et al. 2003).

Die erhöhte B-Catenin-Expression weist auf einen erhöhten hydrostatischen Druck in einer obstruierten Niere bereits zu einem Zeitpunkt hin, zu dem die Induktion der tubulointerstitiellen Fibrose noch nicht stattgefunden hat und hebt somit B-Catenin als einen möglichen molekularen Marker zur Erkennung einer frühen Phase der kongenitalen renalen Obstruktion hervor.

\subsection{Fazit}

Zusammengefasst untermauern die präsentierten bisherigen Ergebnisse die Hypothese, dass das Wnt-Signalsystem eine wichtige Rolle in der Pathophysiologie der kongenitalen obstruktiven Uropathie der Ratte spielt. Die Aktivierungsmechanismen der Wnt-Signalübertragung hängen offensichtlich von der Dauer der renalen Obstruktion ab. In Korrelation mit Ergebnissen der Fachliteratur kann das folgende hypothetische Modell für das Wnt-Signalsystem bezüglich der kongenitalen obstruktiven Uropathie vorgeschlagen werden (Abb. 4.1).

Eine partielle Obstruktion der Niere während der Nephrogenese erhöht den hydrostatischen Druck und beeinflusst dadurch die Adhäsionsmechanismen von Zellen des Tubulussystems, was durch eine erhöhte ß-Catenin-Expression angezeigt wird. Eine verminderte Expression von Wnt-4 in Zusammenhang mit einer gesteigerten Expression von sFRP-1 führt zu einer unzureichenden Tubulogenese. Des weiteren trägt eine vermehrte Expression von sFRP-1 sowie JNK durch Apoptose von Tubuluszellen zu renaler Wachstumsretardierung bei.

Überdauert die renale Obstruktion bei älteren Tieren die Phase der Nephrogenese, so unterstützen die verstärkte Wnt-Signalvermittlung - hervorgerufen durch Überexpression von Wnt-4 und friz-2 - sowie deren synergistische Effekte mit TGF- 
B1 die Entwicklung chronischer Nierenschäden, insbesondere der tubulointerstitiellen Fibrose, deren Ausdehnung eng vergesellschaftet ist mit dem Fortschreiten einer Niereninsuffizienz. Ein weiterer Punkt ist, dass eine Überexpression von WIF-1 durch die Induktion von Apoptose zu tubulärer Atrophie sowie interstitieller Fibrose beitragen könnte. Zusammenfassend lässt sich feststellen, dass die oben beschriebenen Phänomene wie renale Wachstumsretardierung, tubuläre Atrophie, interstitielle Fibrose und als Konsequenz der Verlust der renalen Funktion das Vollbild der kongenitalen obstruktiven Uropathie beschreiben.

Letztendlich ist die Charakterisierung einiger ausgewählter Mitglieder der WntSignalkette auf RNA-Ebene für das Verständnis der Expression und Regulation dieser Gene von großer Wichtigkeit, sie kann jedoch nur als ein erster Schritt zur Orientierung dienen. Noch ist über das Wnt-Signalsystem in Bezug auf die kongenitale obstruktive Uropathie zu wenig bekannt und weitere Studien sind unabdingbar, um diese pathophysiologische Konstellation im Hinblick auf mögliche klinische und therapeutische Verwendung weiter aufzuklären. 


\section{Zusammenfassung}

Ziel: Um die Rolle der Wnt-Signalkette in Hinblick auf die Pathophysiologie der kongenitalen obstruktiven Uropathie der Ratte zu ergründen, wurden in der vorliegenden Arbeit die Expressionsmuster ausgewählter Gene untersucht.

Methoden: Es wurde die totale zelluläre mRNA aus Nieren von Ratten untersucht, die eine vererbte angeborene Hydronephrose aufwiesen. Untersucht wurden sowohl die obstruierten, die kontralateralen sowie die gesunden Nieren der Kontrollgruppe, jeweils im Alter von 14 sowie 32 Tagen. Die mRNA wurde extrahiert und in den einzelnen Gruppen gepoolt. Die mRNA-Expression wurde mittels Real-time reverse transcription-PCR bestimmt.

Ergebnisse: Es wurden signifikante Unterschiede in der Genexpression der obstruierten Nieren gegenüber den kontralateralen sowie den Nieren der Kontrollgruppe ermittelt. Bei den obstruierten Nieren der 14 Tagen alten Tiere war die Expression von Wnt-4 vermindert. Die Expression der secreted Frizzled-related proteins (sFRP-1 und -2), von B-Catenin sowie der Jun N-terminalen Kinase (JNK) war erhöht. Die Genexpression von Wnt-7b, Frizzled-1 und -2, Calcineurin sowie dem Wnt-Inhibitory Factor (WIF-1) war unverändert. Bei den Nieren der 32 Tage alten Tiere war die Expression von Wnt-4, Wnt-7b, Frizzled-2, sFRP-1 sowie WIF-1 erhöht, während die Expression von Frizzled-1, sFRP-2, B-Catenin, JNK und Calcineurin unverändert war.

Schlussfolgerungen: Die Ergebnisse lassen auf eine altersabhängige Rolle der Wnts in der Pathophysiologie der kongenitalen obstruktiven Uropathie der Ratte schließen. Eine herabregulierte Wnt-Signalübertragung zum Ende der Nephrogenese bei den 14 Tage alten Versuchstieren kann ein Hinweis auf eine beeinträchtigte Tubulogenese sein. Die gesteigerte Expression von B-Catenin und JNK weist auf eine Beanspruchung der Zell- zu Zellkontakte, hervorgerufen durch den erhöhten hydrostatischen Druck bei fortschreitender Hydronephrose, hin. Die erhöhte WntSignalübertragung bei den älteren Tieren steuert vermutlich zur Ausbildung der interstitiellen Fibrose sowie der tubulären Apoptose bei.

Diese Arbeit soll als Grundlage dafür dienen, die einzelnen beobachteten Veränderungen der Genexpression im Hinblick auf die kongenitale obstruktive Uropathie in weiteren Arbeiten detailliert zu untersuchen. 


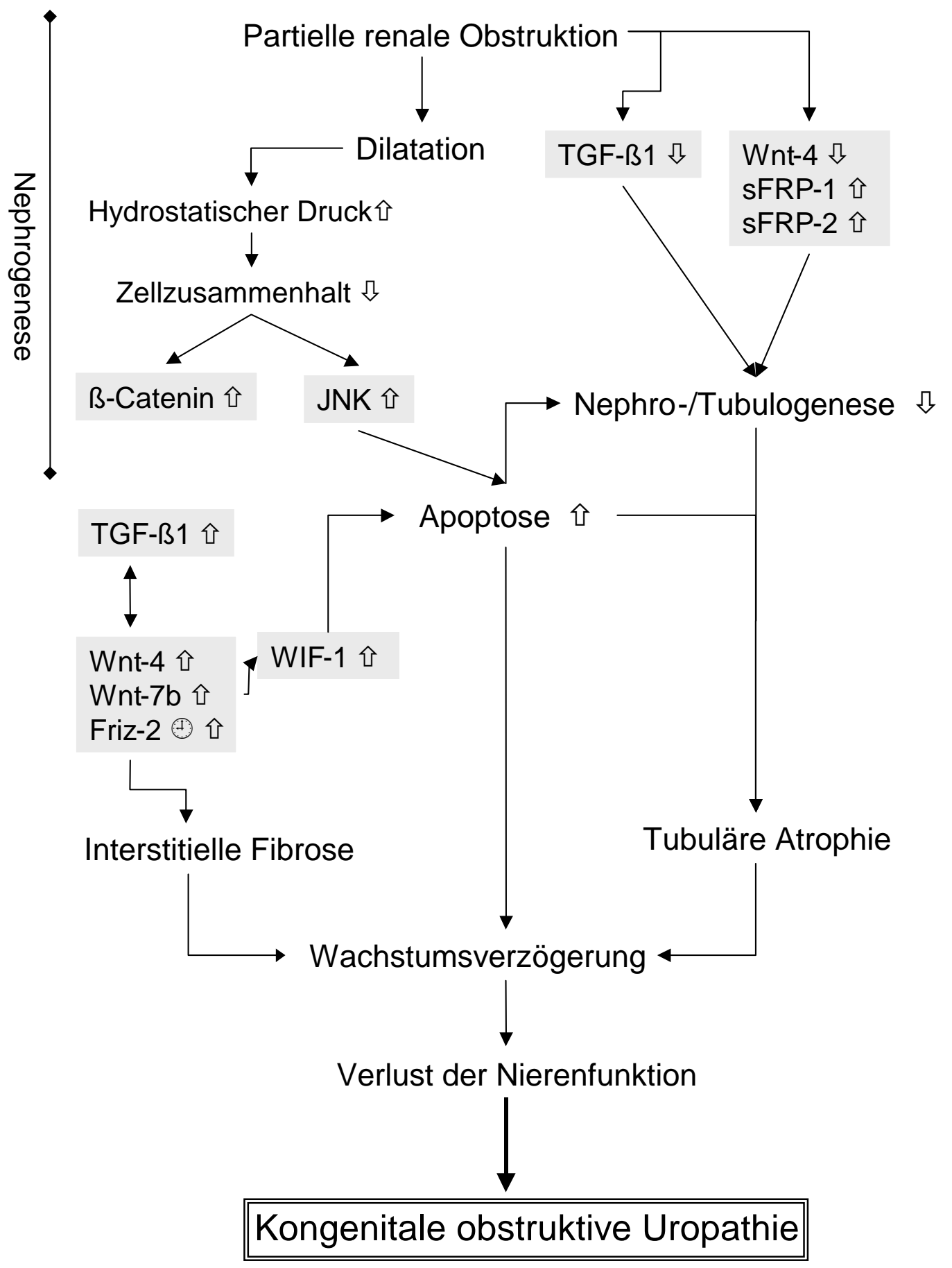

Abb. 4.1: Hypothetisches Modell der Rolle der Wnt-Signalkette in der Pathophysiologie der kongenitalen obstruktiven Uropathie der Ratte. 仓 = erhöht; $\sqrt{\checkmark}=$ erniedrigt 


\section{Literaturverzeichnis}

Aberle H, Butz S, Stappert J, Weissig H, Kemler R, Hoschuetzky H (1994): Assembly of the cadherin-catenin complex in vitro with recombinant proteins. J Cell Sci 107, 3655-3563

Awazu M, Omori S, Hida M (2002): MAP kinase in renal development. Nephrol Dial Transplant 17 (Suppl 9), 5-7

Chevalier RL (1995): Effects of ureteral obstruction on renal growth. Semin Nephrol 15(4), 353-60

Chevalier RL (1999): Molecular and cellular pathophysiology of obstructive nephropathy. Pediatr Nephrol $\underline{13}, 612-619$

Chevalier RL, Chung KH, Smith CD, Fichenec M, Gomez RA (1996): Renal apoptosis and clusterin following ureteral obstruction: the role of maturation. $J$ Urol 156, 1474-1479.

Chevalier RL, Sturgill BC, Jones CE, Kaiser DL (1987): Morphologic corerlates of renal growth arrest in neonatal partial ureteral obstruction. Pediatr Res $\underline{21}$, 338-346

Chomczynski P, Sacchi N (1987): Single-step method of RNA isolation by acid guanidinium thiocyanate-phenol-chloroform extraction. Anal Biochem 162, 156-159

He B, Reguart N, You L, Mazieres J, Xu Z, Lee AY, Mikami I, McCormick F, Jablons DM (2005): Blockade of Wnt-1 signaling induces apoptosis in human colorectal cancer cells containing downstream mutations. Oncogene $\underline{24}, 3054-3058$

Huelsken J, Behrens J (2002): The Wnt signalling pathway. J Cell Sci 115, 39773978

Kawano Y, Krypta R (2003): Secreted antagonists of the Wnt signalling pathway. J Cell Sci 116, 2627-2634 
Kispert A, Vaino S, McMahon AP (1998): Wnt-4 is a mesenchymal signal for epithelial transformation of metanephric mesenchyme in the developing kidney. Development 125, 4225-4234

Klahr S (2001): Urinary tract obstruction. Semin Nephrol 21, 133-45

Masszi A, Fan L, Rosivall L, McCulloch CA, Rotstein OD, Musci I, Kapus A (2004): Integrity of cell-cell contacts is a critical regulator of TGF-beta 1-induced epithelial-to myofibroblast transition: role for B-Catenin. Am J Pathol 165, 1955-1967

Merlet-Benichou C, Gilbert T, Muffat-Joly M, Lelievre-Pegorier M, Leroy B (1994): Intrauterine growth retardation leads to a permanent nephron deficit in the rat. Peditr Nephrol $\underline{8}, 175-180$

Miller JR (2001): The Wnts. Genome Biol $\underline{3}$, 3001.1-3001.15

Nagafuchi A, Shirayoshi Y, Okazaki K, Yasuda K, Takeichi M (1987): Transformation of cell adhesion properties by exogenously introduced E-cadherin cDNA. Nature $\underline{329}$, 341-343

Najarian JS, Almond PS, Gillingham KJ, al. e (1993): Renal transplantation in the first five years of life. Kidney Int Suppl $\underline{43}$, 40-44

Nakamura Y, Nawata M, Wakitani S (2005): Expression profiles and functional analyses of Wnt-related genes in human joint disorders. Am J Pathol 167, 97-105

Nguyen H, Thomson A, Kogan B, Baskin L, Cunha G (1999): Expression of the Wnt gene family during late nephrogenesis and complete ureteral obstruction. Lab Invest $\underline{79}, 647-658$

Ohigashi T, Mizuno R, Nakashima J, Marumo K, Murai M (2005): Inhibition of Wnt signaling downregulates Akt activity and induces chemosenitivity in PTEN-mutated prostate cancer cells. Prostate $\underline{62}, 61-68$ 
Seseke F, Thelen P, Hemmerlein B, Kliese D, Zöller G, Ringert RH (2000): Histologic and molecular evidence of obstructive uropathy in rats with congenital hydronephrosis. Urol Res $\underline{28}(2), 104-109$

Seseke F, Thelen P, Heuser M, Zöller G, Ringert RH (2001): Impaired nephrogenesis in rats with congenital obstructive uropathy. J Urol 165, 2289-2292

Seseke F, Thelen P, Ringert RH (2004): Characterization of an animal model of spontaneous congenital unilateral obstructive uropathy by cDNA microarray analysis. Eur Urol $\underline{45}, 374-381$

Strutt D (2003): Frizzled signalling and cell polarisation. Development 130, 45014513

Surendran K, McCaul S, Simon T (2002): A role for Wnt-4 in renal fibrosis. Am J Physiol Renal Physiol 282, F431-F441

Tauchi K, Suzuki K, Imamichi T (1980): Establishment of a strain of a rat having extremely high incidence of congenital hydronephrosis and its morphological characteristics. Cong Anom 20, 1-6

Terada Y, Tanaka H, Okado T, Shimamura H, Inoshita S, Kuwahara M, Sasaki S (2003): Expression and function of the developmental gene Wnt-4 during experimental acute renal failure in rats. J Am Soc Nephrol 14, 1223-1233

Tian YC, Fraser D, Attisano L, Philips AO (2003): TGF-ß1-mediated alterations of renal proximal tubular epithelial cell phenotype. Am J Physiol Renal Physiol $\underline{285}$, F130-F142

Truong L, Petrusevska G, Yang G, Gurpinar T, Shappell S, Lechago J, Rouse D, Suki W (1996): Cell apoptosis and proliferation in experimental chronic obstructive uropathy. Kidney Int $\underline{50}$, 200-207 
Uren A, Reichsmann F, Anest V, Taylor W, Muraiso K, Bottaro D, Cumberledge S, Rubin J (2000): Secreted frizzled-related protein-1 binds directly to Wingless and is a biphasic modulator of Wnt signalling. J Biol Chem 275, 4374-4382

Vaino S (2003): Nephrogenesis regulated by Wnt signalling. J Nephrol $\underline{16}, 279-285$

Vaino S, Uusitalo M (2000): A road to kidney tubules via the Wnt pathway. Pediatr Nephrol $\underline{15}, 151-156$

Vrljicak P, Myburgh D, Ryan AK, van Rooijen A, Mummery CL, Gupta IR (2003):

Smad expression during kideny development. Am J Physiol Renal Physiol 286, 625633

Wong M, Medrano J (2005): Real-time PCR for mRNA quantitation. Biotechniques $\underline{39}$ (1), 75-85

Xia Z, Dickens M, Raingeaud J, Davis R, Greenberg M (1995): Opposing effects of ERK and JNK-p38 MAP kinases on apoptosis. Science 270, 1326-1331

Yoshino K, Rubin JS, Higinbotham KG, Uren A, Anest V, Plisov SY, Perantoni AO (2001): Secreted frizzled-related proteins can regulate metanephric development. Mech Dev 102, 45-55 


\section{Danksagung}

Ein ganz besonderer Dank geht an meinen Betreuer und zugleich Initiator dieser Arbeit, Herrn Prof. Dr. med. Florian Seseke. Ohne inn und seine Geduld, seine Unterstützung sowie seine fachliche Kompetenz währe diese Arbeit nie möglich gewesen.

Ebenso bedanke ich mich bei Herrn Paul Thelen, der mich besonders in der wissenschaftlichen Durchführung der Laborarbeit sehr unterstützt hat. Auch Frau Marion Striepe als zuständiger Laborantin des urologischen Labors möchte ich an dieser Stelle für ihre Hilfe und Unterstützung, nützliche Tipps sowie ein allseits offenes Ohr ganz herzlich danken. 